\title{
Comportamiento estratégico ante la intervención de las autoridades de la competencia: la industria del pan en España*
}

\author{
José Manuel Ordóñez de Haro \\ José Luis Torres Chacón \\ Universidad de Málaga
}

\section{Resumen}

En este trabajo analizamos los efectos de la intervención de las autoridades de la competencia sobre el precio del pan utilizando el enfoque de las Series Temporales Interrumpidas. Los resultados muestran la existencia de cambios de comportamiento en la evolución del precio de ese producto que se iniciaron, a finales del 2007, con las primeras actuaciones de la Comisión Nacional de la Competencia (CNC) en el sector del pan. Así, antes de la incoación del expediente sancionador por la subida de los precios de los alimentos, se produjo efectivamente un cambio de tendencia al alza en el precio del pan que estaría explicado por las recomendaciones colectivas de subidas de precio realizadas por numerosas asociaciones pertenecientes a la industria del pan. Sin embargo, a partir de la apertura del mencionado procedimiento sancionador, el precio del pan se ha mantenido prácticamente constante. Esto evidencia que la intervención de las autoridades habría disuadido o evitado que se volviera a utilizar el mecanismo de transmisión de información entre las asociaciones y los correspondientes operadores del sector. Esto ha conducido a la insensibilidad de esos operadores a las variaciones en el precio de la materia prima de referencia bien por falta de información para trasladar esas variaciones al precio del pan o bien como consecuencia de seguir un nuevo patrón de comportamiento basado en la colusión tácita.

Palabras clave: industria del pan, política de competencia, precios, análisis de series temporales interrumpidas, efectos disuasorios, efectos correctores, histéresis.

Clasificación JEL: K21, K42, L41, L66.

\begin{abstract}
This paper analyses the effects of the competition authorities' intervention on the evolution of the price of bread using the Interrupted Time Series approach. The results show the existence of behavioral changes in the evolution of bread prices which started at the end of 2007 with the Spanish Competition Authority's first actions. Before the opening of the disciplinary proceeding, there was an upward trend in bread prices, which became steeper after the collective price recommendations issued by various bread associations. However, since the opening of the disciplinary proceeding, the price of bread has remained almost constant. This demonstrates the deterrent effect of the competition authorities' interventions by preventing such a mechanism

* José Manuel Ordóñez de Haro agradece la financiación recibida a través de la Cátedra de Política de Competencia de la Universidad de Málaga y del Proyecto de Investigación SEJ-080065. José Luis Torres agradece la financiación recibida del Proyecto de Excelencia SEJ-1512. Las opiniones expresadas por los autores son estrictamente personales y en ningún caso vinculantes para las instituciones en las que prestan sus servicios. Cualquier error u omisión es también exclusiva responsabilidad de los autores.
\end{abstract}


for sharing price information between the bread associations and the firms participating in the industry. The industry operators are now practically insensitive to price variations in the main referral input because either they do not have enough information about how to pass these input price variations on through the price of bread or they are following a new pattern of behavior based on tacit collusion.

Keywords: bread industry, competition policy, prices, interrupted time series analysis, deterrent effects, remedy effects, hysteresis.

JEL classification: K21, K42, L41, L66.

\section{Introducción}

El estudio de los efectos de la intervención de las autoridades de la competencia ante comportamientos no competitivos en una determinada industria resulta crucial no solo para evaluar la efectividad de este tipo de políticas, sino también para diseñar los mecanismos de actuación adecuados. A este respecto, debería considerarse indispensable el análisis y cuantificación no solo de los efectos a corto plazo de dicha intervención, sino también sus efectos a largo plazo, como elemento clave para valorar correctamente su efectividad.

En un reciente artículo, Ordóñez de Haro y Torres (2014), demostramos la existencia de un efecto no deseado en el comportamiento posterior de los precios de una serie productos alimenticios, entre ellos el pan, como consecuencia de la intervención de la extinta Comisión Nacional de la Competencia (CNC) en las respectivas industrias ${ }^{1}$. Los resultados prueban una drástica reducción de la volatilidad de los precios tras la intervención, que no obedece a la evolución de los precios de las principales materias primas empleadas en cada proceso productivo. Una posible explicación de este comportamiento sería que la intervención de la autoridad habría provocado la ruptura o interrupción del mecanismo principal de comunicación e intercambio de información que utilizaban los operadores de cada industria: su asociación.

En este trabajo nos centramos en analizar cuáles han sido las consecuencias de la intervención de las autoridades españolas de la competencia sobre la evolución del precio del pan. En particular, consideramos los efectos de las decisiones adoptadas tanto por la CNC como por las autoridades autonómicas a raíz de la publicación de numerosas notas de prensa y declaraciones en los medios de comunicación, entre los meses de julio y septiembre de 2007, por parte de representantes de las principales asociaciones pertenecientes al sector del pan, en las que se anunciaban futuras subidas en el precio del pan.

La metodología que emplearemos en el presente trabajo se basa en la aplicación de Series Temporales Interrumpidas (STI). Este método permite estudiar el comportamiento de una determinada variable, el precio del pan en nuestro caso,

\footnotetext{
${ }^{1}$ Actualmente, las funciones de la $\mathrm{CNC}$ se encuentran integradas en la nueva Comisión Nacional de los Mercados y la Competencia (CNMC).
} 
a lo largo del tiempo teniendo en cuenta la posible existencia de intervenciones o cambios de política en el sector. La idea básica consiste en estimar una serie temporal en función de variables ficticias y variables de conteo que reflejen los efectos de una determinada intervención o política en un momento determinado del tiempo y analizar cómo la evolución temporal de dicha variable se ve afectada por dicha intervención.

Los resultados obtenidos muestran un claro cambio de comportamiento en la fijación del precio del pan a partir de la intervención de las autoridades de la competencia. Concretamente, el modelo estimado muestra que la fecha en la que se inspeccionó la sede de la asociación que integra a la mayoría de asociaciones y gremios de fabricantes y expendedores de pan en España, CEOPAN, coincide con un cambio de tendencia al alza del precio del pan, cambio que respondería a los efectos de las recomendaciones colectivas de subidas de precios realizadas por esa y otras asociaciones. No obstante, tras la incoación del expediente sancionador a la mayoría de asociaciones de productos alimenticios y la remisión de una circular informativa por parte de CEOPAN, se rompe la tendencia alcista en los precios habida hasta ese momento, y tiene lugar una situación en la que el precio del pan se ha mantenido prácticamente constante hasta la actualidad.

Este último resultado parece indicar la ruptura o colapso del mecanismo de transmisión de información entre las asociaciones y las empresas del sector respecto a la fijación de precios. Debemos señalar, en este sentido, que la evolución del precio del pan, observada a partir de la fecha de la incoación del expediente sancionador y el envío de la circular, es completamente independiente de la conducta del precio de la materia prima que la industria utilizaba como referencia, el trigo blando panificable. Por tanto, el efecto disuasorio de las intervenciones de las autoridades nacional y autonómicas de la competencia podría haber provocado que las empresas dejaran de reaccionar a modificaciones en el precio de sus factores productivos bien por falta de información o bien como consecuencia de una nueva estrategia consistente en minimizar las fluctuaciones en torno al precio alcanzado tras las recomendaciones. En cualquiera de los dos casos, el resultado ha sido la no corrección de los aparentes efectos de las conductas investigadas y sancionadas.

La estructura del resto del trabajo es la siguiente. En la segunda sección se realiza una revisión de la literatura sobre la existencia de prácticas no competitivas en la industria del pan y los efectos de la actividad llevada a cabo por las autoridades de la competencia en esa industria. La sección tercera presenta los principales rasgos identificativos de la industria del pan en España. En la sección 4 se describen las diferentes decisiones adoptadas por las autoridades de la competencia en España en el sector del pan, con especial consideración de los hechos que son el objeto de estudio en este trabajo. La sección 5 presenta una descripción de los datos, así como del método de análisis utilizado para cuantificar los efectos de la intervención de las autoridades de la competencia. Los resultados se presentan en la sección 6. Finalmente, la sección 7 presenta las principales conclusiones que se derivan del estudio realizado. 


\section{La literatura acerca de los efectos sobre el precio del pan de la intervención de las autoridades de la competencia}

En las últimas décadas ha crecido el interés de la literatura, tanto teórica como empírica, por el análisis del comportamiento de los precios tras una intervención de una autoridad de la competencia ${ }^{2}$. Este interés vendría explicado por la evidencia que proporcionarían estos estudios sobre la efectividad de la aplicación de las normas de defensa de la competencia, corrigiendo los efectos de las prácticas anticompetitivas y disuadiendo de su realización en el futuro, así como sobre los precios que se habrían fijado en ausencia de dichas prácticas, lo que constituiría una información muy útil para las autoridades a la hora de estimar los sobreprecios y daños, en base a los cuales fijar las sanciones correspondientes.

De entre los sectores a los que los autores, en este campo de investigación, le han prestado una especial atención destaca la industria del pan. En particular, el análisis de esta industria en Estados Unidos ha sido el objeto de varios artículos (Parker, 1969; Block et al., 1981; Newmark, 1988a, 1988b; Mueller y Parker, 1992). El trabajo de Parker constituye uno de los primeros trabajos centrados en el análisis de la evolución de los precios en la industria de panadería y sus posibles explicaciones. Este autor también destaca la considerable actividad de las agencias antitrust en esta industria. Plantea como ejemplo lo ocurrido en el Estado de Washington donde la Federal Trade Commission (FTC) concluyó en 1964 que los «Bakers of Washington», una asociación de panaderos con sede en Seattle, era culpable de un acuerdo de fijación de precios. La FTC demostró que los panaderos mayoristas y los detallistas líderes utilizaron las reuniones de la asociación para planificar la conspiración de fijación de precios, con el objeto de aumentar el precio del pan en el estado de Washington. De acuerdo con las pruebas presentadas por la agencia, los precios de Seattle, antes de la conspiración, eran casi idénticos a la media nacional. Por el contrario, durante el periodo en el que transcurrió la conspiración (1955-1964), fueron entre un 15 y un 20 por 100 superiores. Parker indica que, finalizada la actuación de la FTC, se desarrolló una intensa competencia en precios, cayendo el nivel de precios de Seattle muy por debajo de la media nacional. Sin embargo, Froeb et al. (1993) señala que este tipo de comparaciones entre distintos periodos y áreas geográficas son poco fiables, puesto que ignoran las posibles diferencias en costes u otros factores que podrían ser responsables de las diferencias en precios observadas.

En esta línea, Newmark (1988a) critica la validez de la evidencia presentada por la FTC que permitió llegar al veredicto de culpabilidad en el caso anterior. Según Newmark, el mayor precio del pan a nivel detallista en Seattle, comparado con el precio promedio en Estados Unidos, durante el periodo de la supuesta conspiración, fue el resultado de los mayores márgenes a nivel detallista y mayores costes laborales, así como una tasa normal de rendimiento más elevada en todo el oeste de los Estados

\footnotetext{
2 Para una revisión más amplia de la literatura sobre este tema, puede consultarse ORDÓÑEZ DE HARO y TORRES (2014).
} 
Unidos ${ }^{3}$. Asimismo, según este autor, la caída en el precio detallista del pan en Seattle desde 1964 a 1966, que podría inicialmente considerarse como el resultado de la actuación de la FTC, en realidad fue el resultado de la aparición de varias marcas baratas con más baja calidad de pan que empezaron a vender en Seattle, lo que habría forzado a los panaderos líderes a modificar sus estrategias de comercialización para mantener sus cuotas de mercado. Unos años más tarde, sin embargo, Mueller y Parker (1992) proporcionaron argumentos y evidencia que contradecirían el análisis y resultados de Newmark, volviendo a dar crédito a las conclusiones alcanzadas por la FTC sobre la existencia de una conspiración para la fijación de precios, así como la interpretación del posterior comportamiento del precio como un efecto reparador o corrector, resultado de la intervención de la FTC.

Block et al. (1981) comprueban la validez de su modelo teórico utilizando los datos de los márgenes en el precio del pan blanco en las 20 mayores ciudades en el período comprendido entre 1965 y 1976. Estos autores señalan que los procesos, iniciados por la División Antitrust del Departamento de Justicia de los Estados Unidos, en casos en los que se detectaron acuerdos para la fijación de los precios del pan provocaron, para su muestra, la reducción de los márgenes de precios del pan blanco. Esta reducción se explicaría por los efectos disuasorios y reparadores de la aplicación de la política antitrust. Los efectos disuasorios consistirían en el impacto negativo del aumento en la capacidad de aplicación de la ley, medido por el cambio interanual en el valor real del presupuesto de la División Antitrust, y la reducción de los márgenes de precios en las ciudades vecinas de aquellas donde el Departamento de Justicia de los Estados Unidos habría intervenido. Además, estos autores destacan la caída del margen de precios en la ciudad donde un año antes la División Antitrust había procesado a un productor de pan, lo que interpretan como una forma que tendrían las empresas encausadas de reparar los efectos de su conspiración de fijación de precios. No obstante, Newmark (1988b), en un trabajo posterior, pone en duda la fiabilidad de los anteriores resultados empíricos. Por un lado, este autor señala que los estimadores de los efectos disuasorios estarían sesgados al alza como consecuencia de errores en la medida utilizada para representar el precio detallista del pan, así como por errores de especificación en el modelo. Por otro lado, Newmark demuestra que el efecto reparador se fundamenta básicamente en la importancia de una única observación que, además, se podría justificar por razones diferentes a la intervención de la autoridad de la competencia.

Más recientemente, centrado en el estudio del conocido cartel de la harina de trigo en Sudáfrica, Mncube (2013) estima en un rango comprendido entre el 7 y el 42 por 100 los sobreprecios de la harina, consecuencia de los acuerdos de fijación de precios y el reparto de los clientes que realizaron los miembros del cartel entre 1999 y 2007. Tal y como reconoce el autor, estos resultados estarían sujetos a los supuestos impuestos para obtener los hipotéticos precios que habrían regido de no existir el

${ }^{3}$ Este autor destaca que esos mayores precios del pan no eran exclusivamente propios de Seattle, sino que eran iguales e incluso menores que los precios existentes en otras ciudades pertenecientes a esta región. 
mencionado cartel. De hecho, supone que estos precios serían los observados antes de la aparición del cartel y no los precios post-cartel, al experimentar estos últimos un comportamiento anómalo. En particular, muestra que, a continuación del incremento en los precios del trigo, los precios de la harina siguieron subiendo incluso después de que a uno de los miembros del cartel se le garantizara inmunidad dentro del programa de clemencia sudafricano y el cartel terminara, mientras que permanecieron estables o rígidos a la baja cuando los precios del trigo comenzaron a descender. Mncube señala como posibles explicaciones alternativas a este comportamiento de los precios la trasmisión asimétrica a los precios de los cambios producidos en costes, la existencia del mantenimiento de una colusión tácita tras el colapso del cartel, o el posible comportamiento estratégico de los antiguos miembros del mismo para afectar, en último término, el cálculo de las potenciales multas, acorde con la teoría defendida por Harrington (2004).

Esta revisión pone de manifiesto la importante y generalizada controversia existente en la literatura cuando se analizan las razones que subyacen en el comportamiento de los precios, en respuesta a las actuaciones de las autoridades encargadas de defender la competencia. Por tanto, para poder alcanzar conclusiones sólidas se hace necesario un estudio detallado del sector implicado, así como de todas las circunstancias que pudieran afectar al precio del pan.

\section{Rasgos básicos del sector del pan en España}

El pan constituye un bien de primera necesidad para un gran número de hogares españoles. El escaso peso relativo que ocupa el gasto anual medio en pan en el presupuesto total de una familia (aproximadamente el 1,11 por 100 en el año 2013 según la Encuesta de Presupuestos Familiares del INE) hace que, por lo general, su demanda sea poco sensible a las variaciones experimentadas en el precio de este producto. No obstante, las innovaciones acontecidas en el sector, con la correspondiente aparición de nuevos productos sustitutivos, los cambios en los hábitos de alimentación de la población española, así como el comportamiento contra-cíclico del consumo de pan, han supuesto un progresivo descenso a nivel nacional en los niveles de consumo y gasto para este producto. Del análisis de su evolución en la última década, se evidencia que este descenso se ha mostrado mucho más acusado durante el período comprendido entre los años 2008 y 2010. De hecho, solo es a partir del año 2010 cuando se aprecia una cierta estabilización de dichos niveles y una ligera inversión en la tendencia para el año 2013, muy probablemente como consecuencia de los efectos de la prolongada recesión experimentada por la economía española en este período (véase Gráfico 1).

Cabe destacar el extraordinario crecimiento del gasto per cápita en el año 2008 que vendría fundamentalmente explicado por las fuertes subidas en el precio del pan que tuvieron lugar a finales del año 2007 y a lo largo del año 2008. Tal como veremos en el siguiente apartado, aun cuando esos aumentos coincidirían con una 


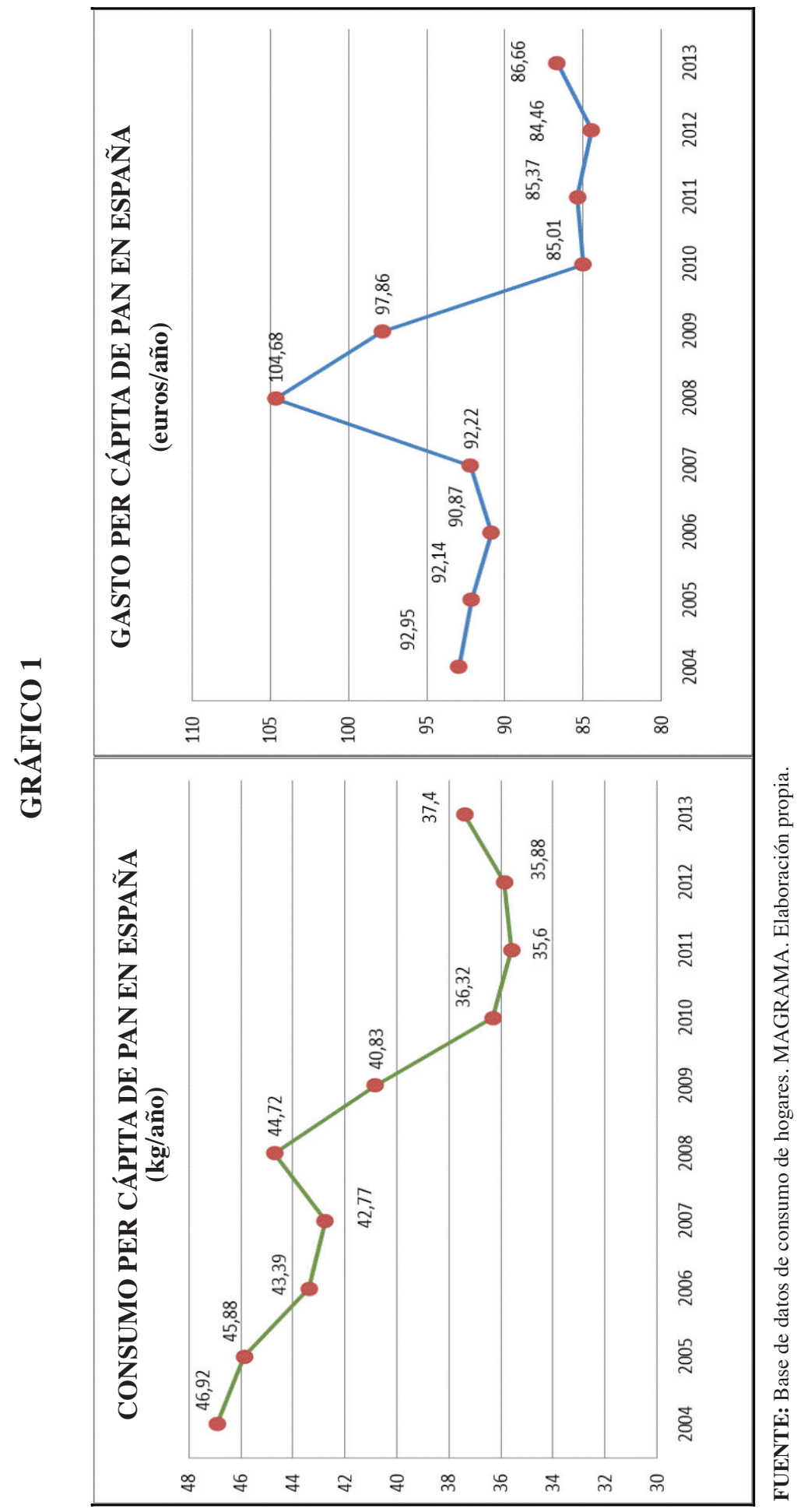


subida sin precedentes en el precio del trigo, tanto la CNC como otras autoridades autonómicas acreditaron la existencia de una práctica anticompetitiva consistente en una recomendación colectiva de subida de precios del pan con una amplia difusión en todo el territorio español, que habría supuesto un aumento que iría más allá de la repercusión del incremento sufrido en el coste del citado factor productivo.

En lo referente al lugar de compra, de acuerdo con la información proporcionada por la «Base de datos de consumo de hogares» del MAGRAMA, las economías domésticas españolas adquieren principalmente el pan en panaderías, en las que se compró el 35,1 por 100 del volumen total en 2013, y en el grupo de establecimientos que englobaría los supermercados y autoservicios, así como los establecimientos de descuento, que vendieron el 45,1 por 100 del volumen total de pan en ese mismo año.Alos anteriores establecimientos les seguirían en importancia, pero a mucha mayor distancia, los hipermercados con el 6,9 por 100 y la tienda tradicional con un 3,8 por 100 . Como se puede observar en el Gráfico 2, la mayoría de hogares ha modificado el lugar donde habitualmente compran el pan. En particular, hasta el año 2009, la panadería era el principal lugar elegido por los consumidores para comprar pan, a partir de ese año, lo adquieren generalmente en supermercados y autoservicios o establecimientos de descuento.

\section{GRAFICO 2}

\section{EVOLUCIÓN DEL PORCENTAJE DE VOLUMEN DE PAN COMPRADO EN LOS DOS PRINCIPALES TIPOS DE ESTABLECIMIENTOS}

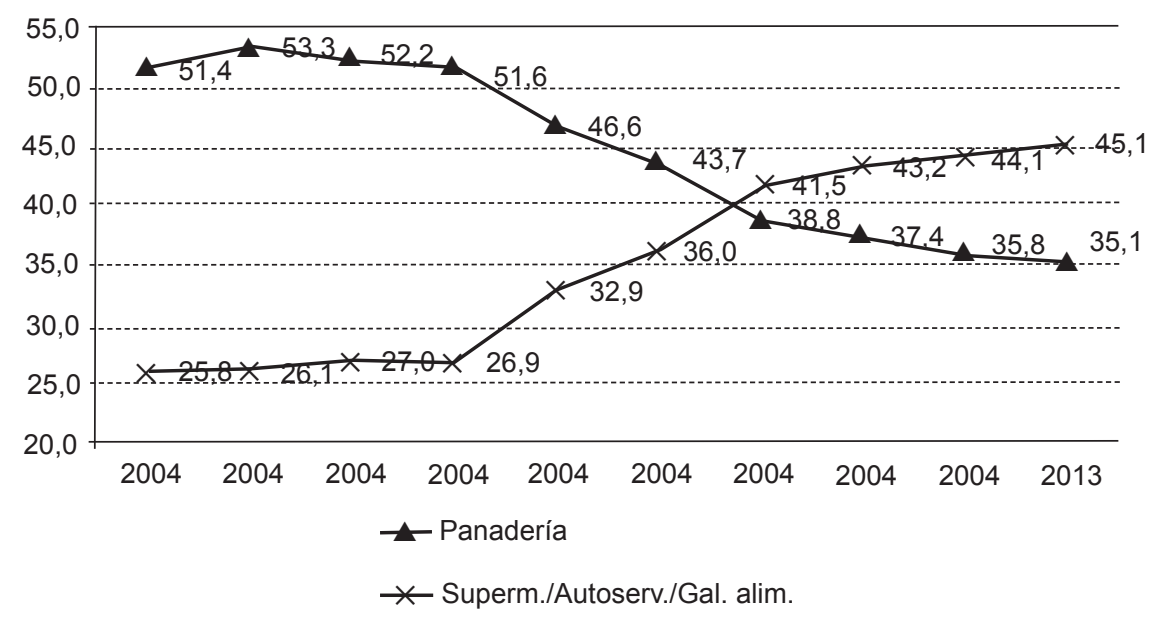

FUENTE: Base de datos de consumo de hogares. MAGRAMA. Elaboración propia. 
En cuanto a características relativas a la oferta de pan, la estructura vertical del proceso de producción del pan está integrada fundamentalmente por tres fases o etapas (véase Cuadro 1) ${ }^{4}$. En la primera fase se encontrarían los productores de materias primas, entre las que destaca la harina. Hay que subrayar que la harina para panificación se obtiene de la transformación del trigo blando panificable que constituye, por tanto, el input principal en este eslabón de la cadena, y representa, aproximadamente, el 75 por 100 del coste de su fabricación. España es netamente importadora de trigo, por lo que los fabricantes de harinas se ven claramente afectados por las fluctuaciones en los mercados internacionales de los precios de este cereal.

Según el «Estudio de la cadena de valor y formación de precios del sector del pan», publicado por el Ministerio de Medio Ambiente y Medio Rural y Marino (MARM), en el año 2009 se encontraban operativas 152 fábricas de harina, localizadas generalmente en zonas productoras de trigo o puertos. De estas fábricas, únicamente 35 empresas alcanzarían una dimensión grande o muy grande, perteneciendo el resto al colectivo de pymes ${ }^{5}$. Además de la importante asimetría en la dimensión de la planta y la consiguiente notable concentración industrial en esta etapa de la producción, los operadores se caracterizan por poseer un exceso de capacidad instalada, provocando una intensa competencia entre ellos, lo que en ciertos casos se traduciría en menores precios y mejores condiciones comerciales para los agentes que integran la siguiente fase productiva ${ }^{6}$.

En esta primera etapa se evidencia un alto nivel de asociacionismo. Concretamente, la Asociación de Fabricantes de Harinas y Sémolas de España (AFHSE), que es la organización empresarial de ámbito nacional que agrupa a las industrias harineras y semoleras de España, integraría al 85 por 100 de los operadores.

\footnotetext{
${ }^{4}$ Entre estas etapas actuarían una serie de operadores que desarrollarían actividades de logística para el abastecimiento del producto obtenido en la etapa inmediatamente anterior (fundamentalmente suministro de harina para la panificación y del producto final o casi terminado a los puntos de venta finales).

${ }_{5}$ Este alto nivel de concentración es el resultado de una reestructuración progresiva e importante de la industria. Según la AFHSE, en el año 1970 existían 1.647 empresas harineras frente a las 152 del año 2009. El Ministerio de Agricultura, Pesca y Alimentación, en un estudio realizado sobre la cadena de producción y distribución del sector de molinería y sus transformados (MAPA, 2003), destacaba que en el sector existía una gran empresa líder que contaba con varias fábricas, un grupo de empresas viables de una cierta dimensión y una gran segmento de pequeñas empresas que difícilmente sobrevivirían a medio plazo, a no ser que encontraran nichos de mercados específicos.

${ }^{6}$ La concentración y la falta de poder de mercado en esta fase del proceso productivo no es exclusiva de España, también en Estados Unidos, como señala Stiegert (2002), se producen estas circunstancias. Este autor apunta a factores institucionales basados en la intensa competencia tanto nacional como internacional presente en este subsector para explicar las limitaciones para ejercer poder de mercado aguas abajo.
} 


\section{CUADRO 1}

\section{ESTRUCTURA VERTICAL DEL PROCESO PRODUCTIVO DEL PAN}

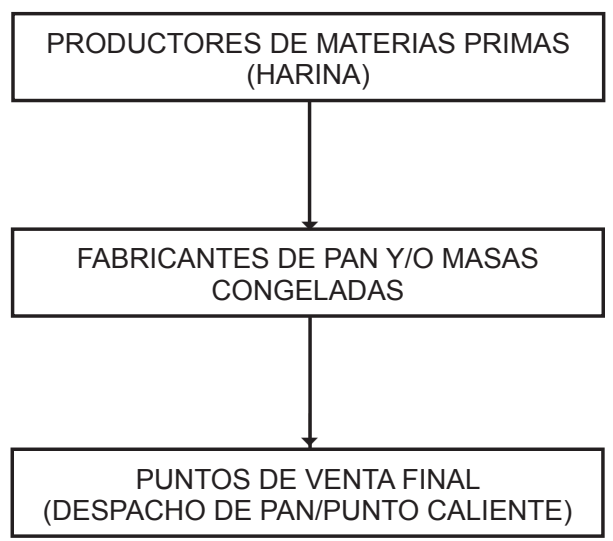

FUENTE: Observatorio de Precios de los Alimentos. MAGRAMA. Elaboración propia.

En la segunda fase del proceso productivo, debemos distinguir entre los agentes que operan en la configuración tradicional de la cadena de valor del pan y aquellos que lo hacen en la configuración moderna:

a) En la configuración tradicional la fabricación del pan corre a cargo de las panificadoras industriales a partir de procedimientos tradicionales, aunque en muchas ocasiones también fabrican y venden masas congeladas o pan precocido congelado. Esta industria posee un elevado grado de atomización, así en el año 2009 existían alrededor de 13.000 empresas activas que producían o comercializaban pan, de estas, únicamente entre 150 y 160 conseguirían alcanzar una facturación anual superior a los 2 millones de euros. En este último grupo, se encontrarían las mayores empresas que se caracterizan por un alto nivel de diversificación en la producción (MARM, 2009). Cabe señalar, asimismo, la importante presencia de integración vertical hacia adelante (forward vertical integration). Así, en el año 2009 cada fábrica de pan controlaba, en promedio, cuatro puntos o despachos de venta, lo que significa que, aproximadamente, más del 33 por 100 de los puntos de venta final eran propiedad o franquicia de alguna fábrica de pan. A pesar de su atomización, el sector de la panificación, considerando tanto las empresas dedicadas a la producción como las dedicadas a la comercialización, se ha consolidado como una importante fuente de creación de puestos de trabajo, y constituye el subsector agroalimentario español que mayor valor agregado y empleo ge- 
nera $^{7}$. La Confederación Española de Organizaciones de Panadería (CEOPAN) es la Asociación que integra en su seno a las Asociaciones y Gremios de fabricantes y expendedores de pan tradicional existentes en España. Estas Asociaciones y Gremios representarían, aproximadamente, el 80 por 100 de la producción de pan.

b) En la configuración moderna esta etapa está participada por los fabricantes de masas congeladas. La existencia de este sector sería relativamente reciente, teniendo sus orígenes en los años ochenta, experimentando un rápido y significativo desarrollo en las últimas décadas ${ }^{8}$, hasta hacerse cargo en la actualidad de una importante parte del abastecimiento que requieren algunas panificadoras y la mayoría de puntos calientes de venta de $\operatorname{pan}^{9}$. A diferencia de lo que ocurre en la configuración tradicional, este sector se encuentra altamente concentrado. De hecho, en el año 2009, las cinco mayores empresas representaban el 76 por 100 de la producción del pan precocido y/o masas congeladas comercializadas en España, otro grupo de empresas acapararía el 15 por 100 , mientras que el 9 por 100 restante se repartiría entre 30 ó 40 empresas que operan también en este segmento (MARM, 2009). El asociacionismo es también una seña de identidad en esta parte de la cadena productiva. En particular, la Asociación Española de Fabricantes de Masas Congeladas (ASEMAC) reúne al 80 por 100 de las empresas y cerca del 90 por 100 de las ventas del sector de masas congeladas.

La última etapa del proceso productivo es la que integran los establecimientos que sirven a la demanda final de pan, cuyo número en el año 2009 ascendía a 156.000 establecimientos. En estos puntos de venta final se distingue entre los despachos de pan propiamente dichos, que representan alrededor del 70 por 100, y los puntos calientes, donde se hornea y vende pan del día, con un 30 por 100 del total. Los primeros abarcarían una amplia diversidad de modelos de venta (tienda tradicional orientada principalmente a la venta de pan, así como microdespachos o puntos de venta en pastelerías, estaciones de servicio, quioscos, carnicerías, charcuterías, bares, etcétera), generalmente con un reducido volumen de venta por establecimiento, y que requieren de un costoso y eficaz sistema logístico de abastecimiento para poder dispensar adecuadamente el pan recién elaborado.

Por otro lado, los puntos calientes serían aquellos despachos de pan que no cuentan con obrador propio, pero que disponen de un horno propio en el que se finaliza la

\footnotetext{
7 Según la información proporcionada por la Confederación Española de Organizaciones de Panadería (CEOPAN) en su página web: http://www.ceopan.es/index.php?type=public\&zone=smartportalcategorias\&action $=$ view $\&$ categoryID $=336 \&$ codeID $=336$ 100 .

${ }^{8}$ Según datos del sector, el crecimiento del sector desde el año 1993 hasta 2011 habría superado el 400 por

9 Tal como pone de manifiesto el estudio de la cadena de valor del pan del MARM, actualmente en torno al 50 por 100 del pan del día consumido en España se habría obtenido a partir de algún proceso en el que se utilizarían masas congeladas, porcentaje que sería mucho más alto en el caso de las grandes ciudades, así como en zonas donde existe una considerable dispersión de los despachos de pan.
} 
confección del pan del día a partir del pan precocido congelado. Por tanto, no necesitan de un complejo y caro sistema de abastecimiento, puesto que atienden in situ y de manera continuada las solicitudes de pan recién hecho. La ventaja principal de este tipo de punto de venta es el significativo ahorro en costes del sistema logístico de abastecimiento, lo que ha promovido su expansión, pudiéndose encontrar puntos calientes de venta de pan en una gran variedad de canales de distribución minorista, estaciones de servicio, establecimientos hosteleros, etcétera.

En resumen, la industria del pan se caracteriza por un elevado grado de atomización en varias etapas de su proceso productivo y habría experimentado una reciente evolución hacia métodos más modernos de confección del pan. Estos métodos conllevan un considerable ahorro en costes de abastecimiento y responden, al mismo tiempo, a la demanda de los consumidores que habitualmente prefieren el pan recién hecho. Estos hechos habrían facilitado su rápida expansión, alcanzando la misma importancia e incluso, en ciertos zonas, relegando a un segundo lugar al método tradicional de producción. Por último, cabe destacar la elevada representatividad que alcanzan las asociaciones en las que se integran los agentes participantes en cada una de las principales etapas de la cadena productiva.

\section{Aplicación de la normativa de defensa de competencia en el sector de la panadería española}

Las autoridades de defensa de la competencia de todo el mundo, conscientes de la importancia que tiene el pan para el bienestar de la mayoría de consumidores y sobre todo para las clases más desfavorecidas, han estado especialmente atentas para detectar, perseguir, y sancionar todas aquellas prácticas anticompetitivas que tuvieran lugar en este sector, en cualquiera de sus etapas productivas ${ }^{10}$. En este sentido, las autoridades españolas de la competencia no han sido una excepción, desarrollando una importante actividad en una industria que ha mostrado signos de ser, cuando menos, conflictiva en materia de competencia. Así, lo demuestra el gran número de resoluciones que las autoridades competentes, nacionales y autonómicas, han dictado a lo largo de las últimas décadas en este sector.

A continuación, ofrecemos una revisión de las decisiones adoptadas por las autoridades españolas de la competencia, en su papel de defensoras de una competencia

\footnotetext{
${ }^{10}$ Cabe reseñar, en el ámbito europeo, las actuaciones llevadas a cabo por las autoridades de la competencia de Alemania, Holanda, Bélgica y Francia para poner fin y sancionar un cartel especialmente dañino integrado por productores de harinas de estos cuatro países y que operó entre los años 2000 y 2008 . Asimismo, particularmente interesantes son las infracciones sancionadas en el sector de la panificación en las que las asociaciones del sector jugaron un papel clave para la coordinación de las prácticas anticompetitivas. A este respecto, podemos citar la decisión del Conseil de la Concurrence de Francia dictada en 2004 en el sector de la panadería en el departamento de Marne, la adoptada en 2008 por la Autoridade da Concorrència de Portugal respecto a las prácticas de la asociación de fabricantes de pan de Lisboa, o finalmente la decisión de 2008 de la Autorità Garante della Concorrenza e del Mercato en Italia relativa a la infracción consistente en las recomendaciones de precios realizadas por la Unione Panificatori di Roma e Provincia, guardando esta última conducta infractora una gran similitud con las conductas ocurridas en España en el mismo periodo de tiempo.
} 
efectiva en la industria del pan. En particular, a efectos de prestar mayor atención a los hechos que son objeto de análisis en los siguientes apartados del trabajo, hemos dividido esta sección en dos epígrafes. En el primero de ellos, hacemos un breve repaso de los expedientes resueltos por el extinto Tribunal de Defensa de la Competencia (TDC) a lo largo del período comprendido entre 1993 y 2007. En el segundo epígrafe, presentamos una exposición más detallada de las notas de prensa y declaraciones por parte de representantes del sector del pan, publicadas entre los meses de julio y septiembre de 2007, y las implicaciones que tuvieron dichas declaraciones en términos de decisiones adoptadas tanto por la también extinta CNC como por las autoridades autonómicas de la competencia.

\subsection{Decisiones del TDC en el período 1993-2007}

En este subapartado pretendemos destacar los elementos comunes que se desprenden del análisis de las decisiones adoptadas por el TDC, que afectaron a empresas u asociaciones que operaban en el sector del pan en el periodo 1993-2007. El Cuadro 2 muestra todas y cada una de las decisiones en ese período, información sobre el tipo de infracción acreditada y correspondiente sanción, así como la existencia, en su caso, de recurso ante la Audiencia Nacional contra la decisión del TDC.

Un primer elemento que se extrae de la revisión de las resoluciones dictadas por el TDC es la implicación crucial e indiscutible de las asociaciones o federaciones del sector en la mayoría de $\operatorname{casos}^{11}$. Este hecho no resulta extraño si tenemos en cuenta que las infracciones acreditadas fueron siempre la recomendación o concertación de precios, así como los acuerdos para limitar la comercialización y producción de pan. Para la coordinación con éxito de una determinada estrategia de precios o comercialización, en un sector como es el de la panificación que, como hemos expuesto en la sección 3 de este trabajo, se caracteriza por un elevado grado de atomización, las asociaciones y gremios del sector pueden constituir un inestimable mecanismo de trasmisión de los objetivos a cumplir, así como de la información relevante que necesitarían los operadores del mercado para su cumplimiento.

\footnotetext{
11 Para las Resoluciones sancionadoras sólo en el expediente 574/04 Panaderías Aranda de Duero no se multó a ninguna asociación del sector, siendo responsables de la conducta infractora una serie de panaderías de aquel municipio.
} 


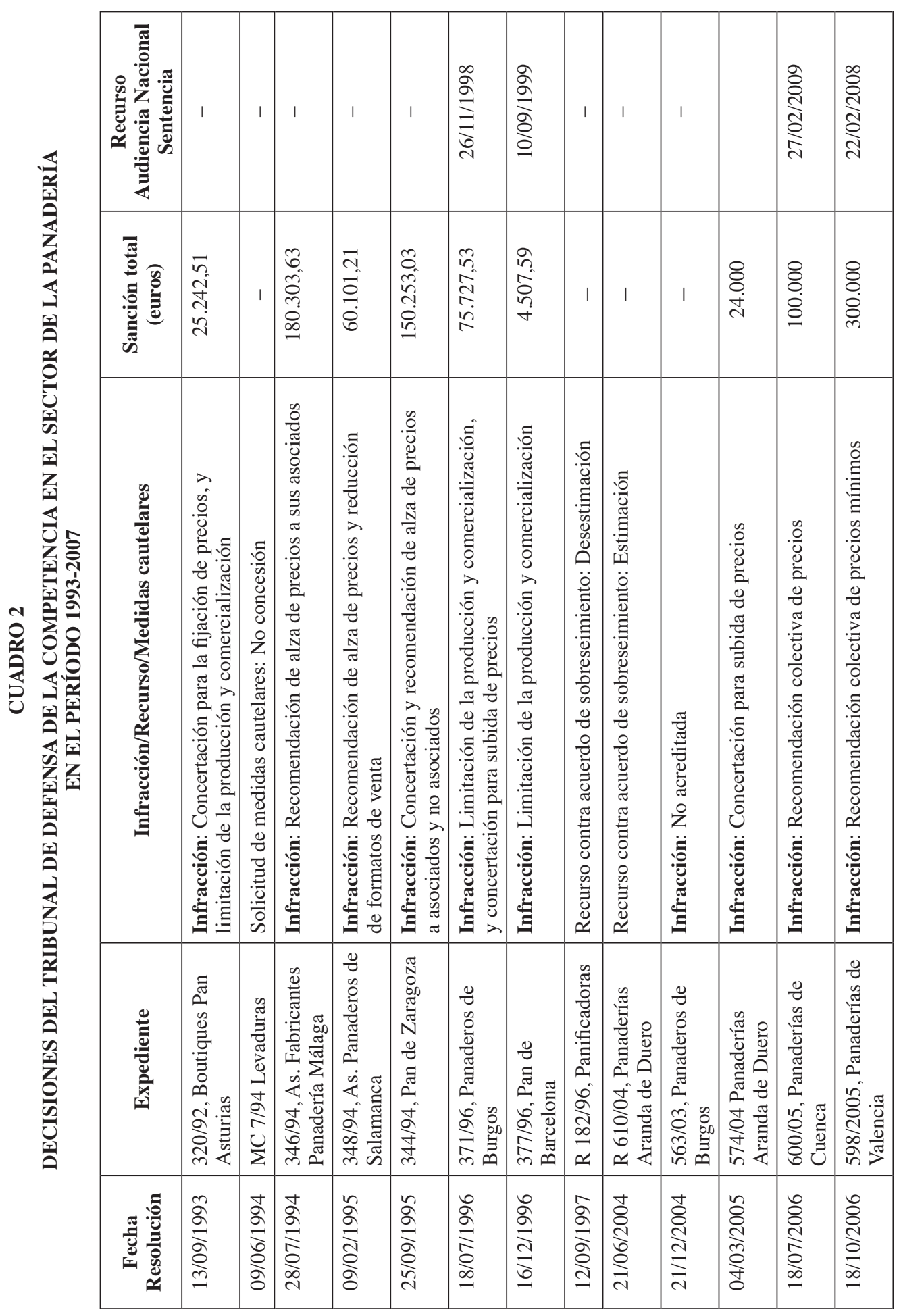


La cuantía de las sanciones fijadas a asociaciones por parte del TDC se encuentra entre los 24.040,48 euros (4 millones de pesetas) impuesta a la Unión de Boutiques del Pan del Principado de Asturias, en el expediente 320/92 Boutiques Pan Asturias, y los 300 mil euros a la Federación Gremial de Panadería y Pastelería de la Provincia de Valencia, en el expediente 598/2005, Panaderías de Valencia. Cabe señalar que en dos expedientes sancionadores, el citado 320/92 Boutiques Pan Asturias y el 371/96, Panaderos de Burgos, el TDC, además de sancionar a la asociación correspondiente, resolvió multar a personas físicas, que ostentaban cargos de dirección en sus asociaciones, por su acreditada intervención en las conductas infractoras ${ }^{12}$.

Por último, en los casos en los que se interpuso recurso contencioso-administrativo contra las Resoluciones dictadas por el TDC, la Audiencia Nacional determinó desestimarlos, declarando ajustadas a Derecho dichas Resoluciones, y en consecuencia confirmándolas. No obstante, cabe significar que, en el contexto del expediente 598/2005, Panaderías de Valencia, la Federación Gremial de Panadería y Pastelería de la Provincia de Valencia interpuso recurso contra la sentencia de la Audiencia Nacional ante el Tribunal Supremo. El Supremo estimó parcialmente dicho recurso en lo concerniente a la cuantía de la sanción, que quedó finalmente establecida en 150.000 euros.

\subsection{El caso «FIAB Y ASOCIADOS Y CEOPAN» y las decisiones en el ámbito autonómico}

Durante el periodo comprendido entre mediados del año 2007 y principios del 2008 , los precios mundiales de las materias primas agrícolas experimentaron subidas sin precedentes. Estos aumentos en los precios se vieron rápidamente traducidos en drásticos incrementos en los precios de los productos alimenticios en todo el mundo, ocasionando un impacto negativo muy importante sobre el bienestar de los consumidores.

En este contexto, entre los meses de julio y septiembre de 2007, algunos representantes de asociaciones y federaciones en el sector español de la alimentación publicaron notas de prensa y declaraciones en los medios de comunicación en las que se anunciaban futuras subidas en los precios de los productos alimenticios. Estos representantes alertaban a la opinión pública del carácter estructural e inevitable de dichos subidas, provocadas por los incrementos en los precios internacionales de las materias primas. En general, estas notas de prensa y declaraciones argumentaban que la subida de los precios en las materias primas era consecuencia del crecimiento de la demanda procedente de economías emergentes, como China e India, así como del desvío cada vez mayor de la producción de cereales a la obtención de biocombustibles.

\footnotetext{
12 En el expediente 320/92 Boutiques Pan Asturias se sancionó con 1.202,02 euros al entonces Secretario de la asociación, y en el expediente 371/96 Panaderos de Burgos a los entonces presidente y secretario de la asociación se impusieron unas sanciones de 3.005,6 y 601,01 euros, respectivamente.
} 
Estos hechos motivaron que la Dirección de Investigación de la Comisión Nacional de la Competencia (CNC) iniciara de oficio, en septiembre de 2007, una investigación en el sector de la alimentación con el objeto de determinar si esas declaraciones y notas podían constituir una infracción del artículo 1 de Ley 15/2007 de Defensa de la Competencia (LDC) ${ }^{13}$.

Como parte de la investigación, la CNC realizó inspecciones sorpresa los días 30 y 31 de octubre de 2007 en una serie de empresas relacionadas con el sector de la alimentación. Entre esas empresas se encontraba también la Confederación Española de Organizaciones de Panadería (CEOPAN).

Durante la instrucción del expediente tuvieron entrada en el registro de la CNC, con fecha 24 de octubre de 2007 y 26 de diciembre de 2007, respectivas denuncias de la Confederación Española de Organizaciones de Amas de Casa, Consumidores y Usuarios (CEACCU) y de la Organización de Consumidores y Usuarios (OCU) contra una serie de asociaciones y federaciones del sector alimentario, entre las que estaban la Federación Española de la Alimentación y Bebidas (FIAB), la Organización Interprofesional Agroalimentaria de Cereales Panificables y Derivados (INCERHPAN-CEOPAN) $)^{14}$ y la Asociación de Fabricantes de Harinas y Sémolas de España (AFHSE). Las organizaciones de consumidores denunciaban que las notas de prensa y las declaraciones en los medios de comunicación por parte de los representantes de esas asociaciones, podrían estar sirviendo como instrumento de comunicación para trasmitir una recomendación colectiva a los operadores en las correspondientes industrias, con el objeto de aumentar los precios. Estas organizaciones también destacaban que, en ciertas ocasiones, los comunicados de prensa incluso llegaban a indicar el incremento concreto que debería aplicarse al precio final de los alimentos ${ }^{15}$. De acuerdo con la OCU y CEACCU, los comunicados de prensa perseguían predisponer a los consumidores para que aceptaran como inevitable la subida de los precios de los alimentos, al estar justificada por el aumento de los costes de producción, y al mismo tiempo coordinar la forma en que los fabricantes deberían actuar. Por lo tanto, estas prácticas constituían una restricción de la competencia contraria al artículo 1 de la LDC.

Hay que señalar que, en aquellas mismas fechas, el elevado precio del pan obligó al Observatorio de Precios del Ministerio de Agricultura, Pesca y Alimentación a publicar en noviembre de 2007 un documento titulado «Información sobre la subida de precio de los cereales y el pan». En dicho documento se argumentaba

13 El artículo 1 de la LDC prohíbe todo acuerdo, decisión o recomendación colectiva, o práctica concertada o conscientemente paralela, que tenga por objeto, produzca o pueda producir el efecto de impedir, restringir o falsear la competencia en todo o en parte del mercado nacional.

${ }^{14}$ INCERHPAN es la Interprofesional Agroalimentaria de la cadena productiva cereales-harina-pan. Está constituida por CCAE, ASAJA, UPA, COAG, AFHSE, CEOPAN Y ASEMAC.

15 Así ocurrió, por ejemplo, en una de las declaraciones en la prensa realizadas por el presidente de la Asociación de Fabricantes de Pan del Principado de Asturias, en la que textualmente establecía que «para compensar el incremento del precio de la harina, la barra de pan tendrá que ponerse en torno a los 90 céntimos antes de que acabe el año». 
que la fuerte subida observada en el precio del pan no encontraría justificación técnica alguna en el aumento del precio del trigo blando panificable ${ }^{16}$.

El Departamento de Investigación de la CNC, una vez analizada la documentación recopilada en las inspecciones, considerando las notas de prensa y declaraciones públicas realizadas por los representantes de las asociaciones, así como las denuncias interpuestas por las organizaciones de consumidores, decidió el 1 de abril de 2008 incoar expediente sancionador a la mayoría de las asociaciones denunciadas. En el caso de CEOPAN, esta decisión se adoptó algún tiempo más tarde, concretamente el 23 de julio de 2008.

La CNC acordó acumular varios expedientes en uno único, S/0053/08 FIAB y ASOCIADOS y CEOPAN, al considerar que entre ellos existía una conexión directa. En concreto, la CNC habría acreditado que las asociaciones y federaciones enjuiciadas en dicho expediente habrían llevado a cabo una estrategia de comunicación e intercambio de información entre ellas para la emisión y distribución de las notas de prensa. Esa comunicación facilitó el conocimiento mutuo de las notas de prensa emitidas por cada una de las diferentes asociaciones, la coordinación en el mensaje que querían trasmitir y su circulación, y por tanto su capacidad para distorsionar la competencia. En este expediente quedaron incluidas, entre otras, las asociaciones pertenecientes a la industria de la panificación CEOPAN y AFHSE ${ }^{17}$.

Durante la instrucción del anterior expediente, la CNC dispuso también de pruebas de otro comunicado de prensa realizado por la Asociación Española de Fabricantes de Masas Congeladas (ASEMAC) que trasmitía mensajes parecidos a los mencionados previamente. En consecuencia, el 25 de mayo de 2009, la Dirección de Investigación de la CNC decidió incoar expediente sancionador a dicha asociación, quedando registrado como S/0133/09 Asociación Española de Fabricantes de Masas Congeladas (ASEMAC).

Asimismo, la CNC tuvo conocimiento de la existencia de declaraciones similares que habrían sido difundidas en los medios de comunicación durante los meses de julio, agosto y septiembre de 2007 por varios representantes de asociaciones provinciales y federaciones regionales de fabricantes de pan. Sobre la base de dichos comunicados, la CNC acordó la incoación de expediente sancionador a la Asociación de Fabricantes de Pan del Principado de Asturias, expediente S/0046/08 Pan de Asturias, mientras que para aquellas declaraciones que partían de asociaciones que operaban en comunidades autónomas con autoridades de la competencia, la CNC decidió remitir esos comunicados a las respectivas autoridades autonómi-

\footnotetext{
16 Más específicamente, establecía que, dado que el coste del trigo representaría como máximo un 10 por 100 del precio de venta al público del pan, «por cada 10 céntimos que subiera el trigo, la barra de pan debería subir como máximo un céntimo, si el resto de costes permanece constante». Por tanto, según el Ministerio, subidas superiores a esta proporción no estaban justificadas.

17 También era parte infractora en el citado expediente la Asociación Española de Panificación y Pastelería de Marca (PPM). No obstante, aunque conexa a la industria analizada en este trabajo, esta asociación representaría al sector del pan y la pastelería industrial de marca.
} 
cas $^{18}$. Estas últimas serían las encargadas de investigar, concluir si existían indicios suficientes de infracción de las normas de competencia y, en caso afirmativo, abrir el correspondiente expediente sancionador. El Cuadro 3 resume todos los expedientes abiertos y decisiones adoptadas tanto por la CNC como por las autoridades autonómicas de la competencia en este ámbito.

La primera Resolución dictada por el Consejo de la CNC correspondió al expediente S/0046/08 Pan de Asturias. El Consejo estimó que las reiteradas declaraciones por parte del Presidente de la Asociación de Fabricantes de Pan del Principado de Asturias a un periódico de ámbito regional constituían una recomendación colectiva de precios. De acuerdo con lo establecido por el Consejo, el objetivo de dichas declaraciones habría sido que los fabricantes y/o detallistas, fuesen o no miembros de la mencionada asociación, reaccionaran de manera colusoria al incremento en los precios de las materias primas, fijando un precio común de la barra de pan en 90 céntimos de euro antes de que finalizara el año 2007. El 24 de septiembre de 2009, el Consejo determinó que la recomendación colectiva constituía una infracción del artículo 1 de la Ley 16/1989, de Defensa de la Competencia e impuso una sanción de 22.500 euros a la asociación.

Por otro lado, el 10 de octubre de 2009, el Consejo de la CNC resolvió el expediente $S / 0053 / 08$ FIAB y ASOCIADOS y CEOPAN. Esta resolución se dictó una vez que quedó acreditado que la FIAB y otras ocho asociaciones o federaciones del sector de la alimentación, entre las que se encontraban, tal y como hemos mencionado previamente, CEOPAN y AFHSE, mediante la emisión y difusión de las notas de prensa, y la colaboración entre esas asociaciones, eran responsables, cuando menos por negligencia, de implementar una recomendación colectiva contraria al artículo 1 de la LDC. De conformidad con lo expuesto por el Consejo en su decisión, el objetivo de esa recomendación era trasladar los incrementos en los costes de las materias primas al precio final pagado por los consumidores. El Consejo de la CNC estimó que en el caso de la AFHSE concurrían circunstancias atenuantes, ya que su nota de prensa era la que presentaba un contenido más neutro, sin ninguna referencia a precios. En base a todo lo anterior, el Consejo, en el marco de este expediente, impuso una multa de 270 mil euros a CEOPAN y de 15 mil euros a AFHSE.

Dentro del presente contexto, la última resolución del Consejo de la CNC se dictó en el expediente S/0133/09 ASEMAC. En este caso, solo existía evidencia de declaraciones puntuales realizadas por el Presidente de ASEMAC a la agencia de noticias EFEAGRO. Más concretamente, en una entrevista telefónica con un periodista de la citada agencia, el Presidente de la asociación anticipaba un incremento del 5,5 por 100 en el precio del pan a partir del mes de septiembre de 2007 debido

18 Esta asignación se realizó conforme a lo establecido en el artículo 1.3 de la Ley 1/2002, de 21 de febrero, de Coordinación de las competencias del Estado y de las Comunidades Autónomas en materia deDefensa de la Competencia, que atribuye competencias ejecutivas a las Comunidades Autónomas respecto de los procedimientos que tengan por objeto las conductas previstas en los artículos 1, 2 y 3 de la LDC, cuando las citadas conductas, sin afectar a un ámbito superior al de una Comunidad Autónoma o al conjunto del mercado nacional, alteren o puedan alterar la libre competencia en el ámbito de la respectiva Comunidad Autónoma. 
al aumento en los costes de producción, principalmente de las materias primas. Sin embargo, contrastando con otros expedientes, no se había proporcionado evidencia acreditando que la asociación hubiese celebrado reuniones para tratar esta cuestión, por lo que el Presidente de ASEMAC podría estar expresando su opinión personal, y no la de la asociación, cuando respondía a las preguntas realizadas por el periodista. Consecuentemente, el 10 de febrero de 2010, el Consejo de la CNC estableció que no había quedado acreditada la infracción, procediendo al archivo de las actuaciones y la no incoación de expediente sancionador contra ASEMAC ${ }^{19}$.

En lo que respecta a las decisiones adoptadas por las autoridades autonómicas de defensa de la competencia, el Tribunal Vasco de Defensa de la Competencia fue la primera autoridad en reaccionar a una noticia aparecida en la prensa que afirmaba que una panadería de Bilbao había recibido una carta de la Asociación de Panaderos de Vizcaya instándole a subir el precio de sus productos. Sin embargo, tras evaluar la información recabada a lo largo de la instrucción del expediente, esta no permitió acreditar una infracción de la LDC por lo que el Tribunal decidió en diciembre de 2008 no incoar expediente sancionador a la asociación, y archivar las actuaciones realizadas referentes al supuesto acuerdo o recomendación de fijación del precio del pan en Vizcaya.

Una decisión similar a la anterior alcanzaron, en el año 2010, tanto el Tribunal para la Defensa de la Competencia de Castilla y León como la Autoritat Catalana de la Competència en sus respectivos expedientes (véase Cuadro 3). La investigación en el primero de los casos se inició por la denuncia presentada por una organización de consumidores de Ávila aportando como prueba unas declaraciones hechas por el Presidente de la Asociación Abulense de Empresarios de Panadería en un programa radiofónico donde realizaba el anuncio previo de una subida de precios en todos los establecimientos abulenses comercializadores de pan común. En el segundo, la apertura del expediente estuvo motivada por el envío por parte de la CNC de una noticia aparecida en la versión digital de un diario nacional que difundía unas declaraciones del presidente del Gremio de Panaderos de la Provincia de Barcelona acerca de la necesidad de subir el precio del pan. En ambos expedientes, TDC/SAN/1/2010, Panaderías de Ávila y 4/2009 (Gremio de Panaderos de Barcelona), el correspondiente órgano instructor llegó a incoar expediente sancionador a la asociación implicada. No obstante, las dos autoridades autonómicas de la competencia determinaron finalmente que no había resultado acreditada la recomendación colectiva por parte de esas asociaciones y resolvieron el archivo de sus respectivas actuaciones.

19 Antes de continuar, nos gustaría señalar lo contenido en una resolución más reciente del Consejo de la CNC, específicamente la dictada el 10 de julio de 2013 en el expediente S/376/11 Panaderías Pamplona. En los «Antecedentes de Hecho» de dicha resolución, se expone que un particular puso en conocimiento de la Dirección de Investigación de la CNC una supuesta subida generalizada de los precios del pan en la ciudad de Pamplona y su comarca en el mes de febrero de 2011. Asimismo, destacaba el informante que este mismo tipo de subida se dio también en 2008 y que el pan en Pamplona y su comarca era uno de los más caros de toda España. Resulta, cuando menos, llamativo que la información proporcionada por el particular también hiciera mención a lo sucedido en el año 2008, momento en el que tuvieron efecto muchas de las recomendaciones que estamos comentando en este epígrafe. 
En lo referente a los expedientes donde las infracciones quedaron acreditadas, y las autoridades sancionaron a sus responsables, se encuentran las decisiones adoptadas por los órganos encargados de defender la normativa de la competencia en Galicia y Andalucía.

El Pleno del Tribunal Gallego de Defensa de la Competencia sancionó con 31.750 euros a la Federación Gallega de Asociaciones Provinciales de Fabricantes de Pan (FEGAPAN) por llevar a cabo una recomendación colectiva de fijación del precio del pan contraria a la LDC. El expediente se inició por la remisión por parte de la Dirección de Investigación de la CNC de unas declaraciones realizadas por responsables de la citada federación, recogidas en los medios de comunicación en agosto de 2007, en las que se hacía referencia a inminentes e inevitables incrementos de los precios del pan en Galicia como consecuencia del encarecimiento de las materias primas.

La actuación de la Agencia de Defensa de la Competencia de Andalucía (ADCA) merece una especial atención tanto por la información sobre las prácticas enjuiciadas en sus resoluciones, como sobre los posibles mecanismos de coordinación de respuestas del sector antes y después de la intervención de la $\mathrm{CNC}$. El primero de los expedientes iniciados por la ADCA tuvo su origen en un escrito remitido por la Dirección de Investigación de la CNC informando de unas declaraciones realizadas por el Presidente de la Federación de Fabricantes de Pan de Sevilla y Provincia (FEPAN) a una agencia de noticias, difundidas en septiembre de 2007. En dichas declaraciones, el presidente de la asociación habría anunciado una subida del precio del pan. Asimismo, se constató la existencia de una cláusula anticompetitiva en los Estatutos de la asociación. El Consejo de Defensa de la Competencia de Andalucía (CDCA) consideró probada la existencia de infracciones de la LDC consistentes en una recomendación colectiva de precios de pan fresco sin envasar en la provincia de Sevilla, y una cláusula ilícita en sus Estatutos, determinando una sanción total para ambas infracciones de 45.067 euros.

Durante la instrucción de este expediente, el Departamento de Investigación de la ADCA tuvo conocimiento de otras cláusulas estatutarias, y declaraciones semejantes en medios de comunicación realizadas por representantes de asociaciones andaluzas del pan. En una de ellas, el presidente de la Asociación Provincial de Panaderos de Málaga (APROPAN) anunciaba, en agosto de 2007, a un diario local una subida de 5 céntimos de la barra de pan normal, y otra del 16 por 100 del pan de elaboración más costosa. Tras considerar las pruebas recabadas a lo largo de la instrucción del expediente, el CDCA declaró acreditada una infracción consistente en una recomendación colectiva de fijación de precios del pan fresco sin envasar en la provincia de Málaga y sancionó a APROPAN con 32.560 euros.

El expediente a la Asociación Provincial de Fabricantes y Expendedores de Pan de Córdoba (AFEPANCOR) se inició al tenerse conocimiento por parte de la ADCA de una cláusula incluida en los Estatutos de esa Asociación que le capacitaba para regular la competencia y cooperar en la fijación del precio del pan en la provincia de Córdoba. Tras proponer la asociación unos compromisos que subsanaban los efectos 


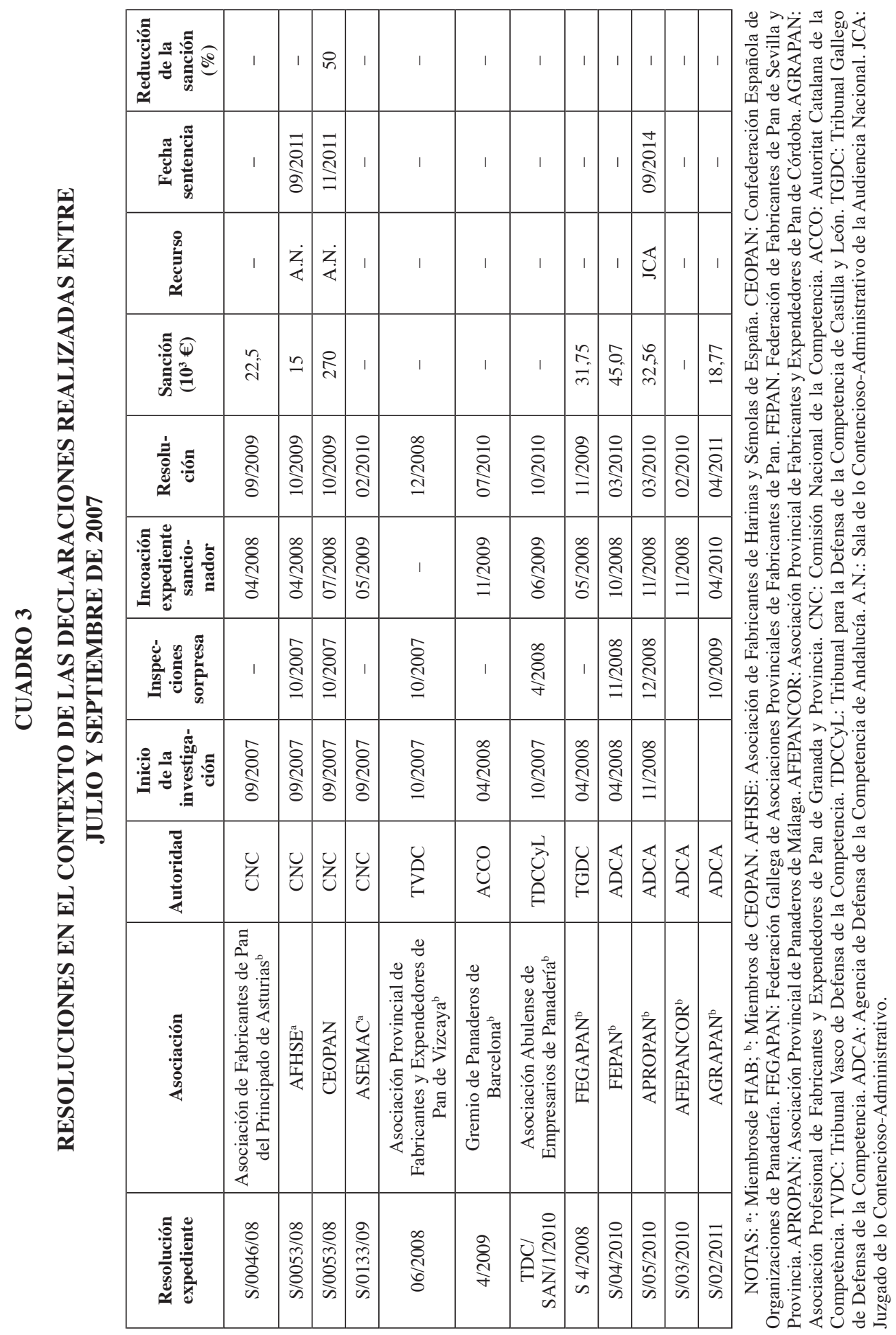


derivados de la conducta infractora, el CDCA acordó la terminación convencional en ese expediente.

En base a otra noticia publicada en una página web, así como en una serie de declaraciones efectuadas por el Presidente de la Asociación Profesional de Fabricantes y Expendedores de Pan de Granada y Provincia (AGRAPAN) a una agencia nacional de noticias, en agosto y septiembre de 2007, y difundidas posteriormente en versiones digitales de la prensa local, el CDCA determinó sancionar a la citada asociación granadina, en la Resolución $S / 02 / 2011$, AGRAPAN, con 18.770 euros por una conducta prohibida consistente en una recomendación colectiva de fijación de precios del pan fresco sin envasar en la provincia de Granada. Posee particular interés para la interpretación de los resultados que se exponen en posteriores secciones, lo descrito en el quinto punto de los «Hechos Probados» de esta resolución. En dicho punto, se establece que entre la documentación recabada en la inspección realizada en la sede de AGRAPAN, figuraba una circular de 8 de abril de 2008, enviada por CEOPAN, informando sobre la incoación de expediente sancionador en relación con la subida de precios de los alimentos por parte de la $\mathrm{CNC}$, conteniendo las siguientes instrucciones:

- «Evitar todo tipo de declaraciones y comunicados (la experiencia del pasado verano nos debería haber enseñado) que pudieran ser problemáticos con la normativa de competencia.»

- «Informarnos inmediatamente de cualquier asunto referente a las acciones de la CNC o de los Tribunales Autonómicos de la Competencia (donde los hubiere) para que podamos darle traslado al Despacho de Abogados que nos está llevando este asunto a CEOPAN.»

En otras palabras, asumiendo que esta circular habría sido remitida a todos los miembros de CEOPAN, todas las asociaciones regionales o provinciales de fabricantes de pan conocieron a partir de ese momento, sin ningún género de dudas, las actuaciones de las autoridades de la competencia y se podrían haber coordinado para desarrollar una respuesta común frente a dichas actuaciones.

\section{Datos y método de análisis}

\subsection{Método de análisis}

El método que consideraremos en nuestro estudio es el denominado Series Temporales Interrumpidas (Interrupted Time Series). Se trata de un análisis de regresión temporal simple cuyo uso está muy extendido en ciencias sociales y del comportamiento. Este tipo de herramienta resulta especialmente adecuada para evaluar el impacto, a lo largo del tiempo, de un determinado tratamiento o intervención sobre un individuo en particular. A este método también se le denomina análisis de series temporal cuasi-experimental y fue inicialmente desarrollado por Campbell y 
Stanley (1963) y Campbell (1969) en el campo de investigación de los efectos de las políticas educativas, siendo posteriormente aplicado a una gran variedad de áreas ${ }^{20}$. Ejemplos de aplicación de este método son los trabajos de Lewis-Beck (1979) para estudiar el efecto de los conflictos armados sobre el comercio internacional y el de Lewis-Beck y Alford (1980) para analizar el efecto de las políticas regulatorias de seguridad sobre los accidentes en la minería de los Estados Unidos.

El nombre de Series Temporales Interrumpidas (STI) proviene de que el tratamiento supone la interrupción de la series en un determinado momento del tiempo. Esta interrupción puede consistir tanto en un cambio de nivel como en un cambio de tendencia, o bien ambos. En el primer caso estaríamos recogiendo el efecto de impacto de la intervención en el momento en el cual se produce, mientras que el segundo reflejaría los efectos de dicha intervención a lo largo del tiempo. La identificación de esta interrupción nos permite cuantificar los efectos del tratamiento o de la intervención realizada. El objetivo de este análisis es detectar la posible existencia de un cambio en el patrón de comportamiento de la serie, antes y después de la intervención, que sea atribuible a dicho evento. Por tanto, el fin último de la aplicación de este método es detectar si la intervención ha tenido consecuencias sobre la evolución temporal de la variable o variables objeto de estudio y cuantificarlas.

La aplicación de este método únicamente requiere una serie temporal para cada sujeto objeto de estudio y las fechas en las cuales se produce el evento, la intervención o el cambio en la política. Considerando la limitada exigencia de datos para su aplicación y el gran valor de sus resultados, esta metodología puede constituir un instrumento adecuado para evaluar los efectos de políticas públicas o hechos relevantes acontecidos en un determinado sector.

En su versión más simple, el modelo de STI determina que el valor de una determinada variable, $\mathrm{x}_{\mathrm{t}}$, puede representarse como sigue:

$$
x_{t}=\beta_{0}+\beta_{1} T+\beta_{2} D_{1}+\beta_{3} T_{1}+\varepsilon_{t}
$$

donde $\mathrm{T}$ es una tendencia temporal para la totalidad del periodo, tomando valor 1 en el primer periodo, 2 en el segundo, y así sucesivamente, $\mathrm{D}_{1}$ es una variable ficticia que toma valor 1 a partir del momento de la intervención y cero en caso contrario, y $\mathrm{T}_{1}$ es una variable de conteo que toma el valor cero desde el principio del periodo muestral hasta la fecha en la que se produce o comienza la intervención, el valor 1 en el primer periodo en que tendría efecto la intervención, 2 en el segundo periodo y así sucesivamente, y $\varepsilon_{t}$ es una perturbación no correlada con media cero. El efecto de la intervención puede ser de dos tipos. Por una parte, puede producirse un cambio en el término constante, lo que implicaría un cambio en el nivel de la serie. Esto sucedería cuando el parámetro estimado de la variable ficticia fuese significativamente diferente de cero. Un valor estimado positivo indicaría un efecto positivo de la

20 Una revisión sobre la aplicación de este método a las ciencias sociales puede encontrarse en McDOWALL et al. (1980) y LEWIS-BECK (1986). 
intervención o política, mientras que un valor negativo indicaría lo contrario. Por otra parte, la variable de conteo $\mathrm{T}_{1}$ reflejaría los efectos permanentes en el tiempo de dicha intervención. Así, la tendencia temporal que sigue la variable a partir del momento de la intervención vendría dada por la suma de los coeficientes estimados de la tendencia general y de la variable de conteo: $\beta_{1}+\beta_{3}$. Si el coeficiente estimado para la variable de conteo no resulta ser significativo, esto se interpretaría como que la intervención no tiene efectos permanentes en el tiempo sobre la evolución temporal de la variable. En esta especificación simple del modelo se está asumiendo que no existen otras variables explicativas relevantes, en caso contrario deberían introducirse en el modelo para controlar los efectos que las mismas tendrían en la variable explicada y, de esta manera, evitar estimadores sesgados como consecuencia de errores de especificación. Teniendo presente lo anterior, la principal ventaja de este modelo es que mediante una regresión simple se pueden recoger tanto los efectos transitorios como los efectos permanentes de una determinada intervención o cambio de política sobre la evolución temporal de una serie particular.

Si bien este tipo de técnica puede resultar muy útil para académicos, profesionales y autoridades interesadas en la investigación de los efectos de las conductas anticompetitivas y la efectividad de la aplicación de las normas de la competencia, no existen muchas referencias en la literatura antitrust en las que se utilice este método. De hecho, para nuestro conocimiento, solo cabría citar a Stano y Hotelling (1991). Estos autores, aunque sin referirse explícitamente a esta técnica, consideran la utilización de una variable ficticia binaria para comprobar la existencia de un cambio adverso en los ingresos de los agentes afectados por un supuesto boicot anticompetitivo. Este enfoque sencillo sería en realidad la versión más básica de la técnica de STI.

Una vez constatada la utilidad del método de STI para comprobar los efectos de la intervención de las autoridades de defensa de la competencia en el precio del pan, hay que indicar que el sujeto en nuestro estudio sería la industria del pan, mientras que la serie temporal se correspondería con el precio del producto representativo de dicha industria. Las fechas de intervención se corresponderían con los distintos momentos o etapas en las que la autoridad de la competencia adopta decisiones relevantes en relación con el procedimiento iniciado en esta industria. En particular, nos centraremos en las decisiones que se adoptaron por las autoridades de la competencia en respuesta a la publicación en los medios de comunicación de notas de prensa y declaraciones de responsables de las asociaciones del sector del pan entre los meses de julio y septiembre de 2007. Estas decisiones se encuentran recogidas en el apartado 4.2 del presente trabajo.

\subsection{Datos}

Los datos para el precio del pan en España se han obtenido de la serie mensual del índice de precios de consumo (IPC) nacional para la rúbrica pan, publicada por el Instituto Nacional de Estadística (INE), correspondiente al periodo de enero 
2002 a agosto de 2014. Asimismo, a efectos de controlar posibles cambios en los costes de los factores productivos, y teniendo en cuenta la información incluida en los informes del sector, así como lo contenido en los expedientes significados, se ha considerado el input cuyo precio constituye la referencia más importante para determinar el precio del pan. Concretamente, hemos seleccionado el precio mensual del trigo blando panificable en España para el mismo periodo muestral. Los datos relativos a esta variable se han extraído de la información publicada por el Boletín Mensual de Estadística del MAGRAMA sobre el precio medio nacional (euro/tm.) del trigo blando panificable. Tal y como se ha expuesto en la sección 3, el trigo blando panificable constituye el input principal de la fabricación de harina, y esta a su vez es un ingrediente esencial para elaborar el pan, de ahí que en general las fluctuaciones en el precio del trigo se habrían traducido en variaciones en el precio del pan.

Por lo que respecta a las fechas de las decisiones o hechos relevantes que tuvieron lugar a lo largo del desarrollo y resolución de los procedimientos administrativos iniciados por las autoridades de la competencia, hemos considerado como más destacadas las siguientes:

- 31 de octubre de 2007: Esta fue la fecha en la que se realizó una inspección sorpresa en la sede de CEOPAN por parte de personal de la Dirección de Investigación de la CNC. En realidad, a efectos de la construcción de las variables a las que incumbe esta decisión en el modelo, hemos considerado el mes de noviembre.

- Abril de 2008: El 1 de abril de 2008 se decidió incoar expediente sancionador a la mayoría de asociaciones implicadas en la subida de los precios de los alimentos (entre ellas AFHSE). Aunque la incoación de expediente sancionador a CEOPAN fue algo más tardía, julio de 2008, debemos recordar la trascendencia que habría tenido la circular que habría remitido la anterior confederación, el 8 de abril, a todos sus miembros. En dicha circular, se alertaba sobre las actuaciones de la CNC, así como se trasmitían las instrucciones que deberían seguir a partir de entonces sus miembros (veáse el segundo epígrafe de la cuarta sección). Por tanto, resulta esencial para nuestro estudio determinar si, desde entonces, los miembros de CEOPAN podrían haber adoptado una pauta de comportamiento común, basada en las recomendaciones recibidas desde la confederación nacional.

- 14 de octubre de 2009: En esta fecha el Consejo de la CNC dictó resolución en el expediente S/O053/08, FIAB Y ASOCIADOS Y CEOPAN, sancionando tanto a CEOPAN como a AFHSE con multas de 270 mil euros y 15 mil euros, respectivamente. De esta manera, el Consejo ponía fin a la vía administrativa, cabiendo la posibilidad de que los interesados interpusieran recurso contencioso-administrativo ante la Audiencia Nacional.

- 10 de noviembre de 2011: Aunque existe una sentencia previa de la Audiencia Nacional desestimando el recurso interpuesto por AFHSE, hemos considerado relevante la sentencia de la misma Sala estimando parcialmente el recurso 
presentado por CEOPAN contra la Resolución dictada por la CNC. En particular, la Audiencia redujo a 135 mil euros la sanción impuesta a CEOPAN.

\section{Resultados}

Tal y como hemos descrito brevemente en la sección anterior, nuestro análisis se centrará en la aplicación del método de Series Temporales Interrumpidas para analizar la evolución del precio del pan en España, en el periodo muestral comprendido entre enero 2002 a agosto de 2014. El modelo a estimar incluye las diferentes fechas de intervención descritas anteriormente. De forma adicional, controlamos la evolución del precio utilizando el precio del trigo blando panificable, que constituye la principal referencia en el sector para la fijación del precio del pan.

El modelo general estimado es el siguiente:

$$
x_{t}=\beta_{0}+\beta_{1} T+\beta_{2} D_{1}+\beta_{3} T_{1}+\beta_{4} D_{2}+\beta_{5} T_{2}+\beta_{6} D_{3}+\beta_{7} T_{3}+\beta_{8} D_{4}+\beta_{9} T_{4}+\beta_{10} \text { Input }_{t}+\varepsilon_{t}
$$

donde $\mathrm{D}_{1}$ hace referencia a la fecha en la cual se llevó a cabo la inspección en la sede de CEOPAN por parte del personal de la CNC tomando el valor cero hasta dicha fecha y tomando el valor 1 a partir del mes de noviembre de 2007 inclusive. $T_{1}$ toma el valor 0 hasta dicha fecha, tomando el valor 1 en noviembre de 2007, 2 en diciembre de 2007, y así sucesivamente. $\mathrm{D}_{2}$ es una variable ficticia que representa la fecha en la cual se inició el procedimiento sancionador para la mayoría de asociaciones y se remitió la mencionada circular por CEOPAN a sus miembros (abril de 2008). Por tanto, esta variable toma el valor cero hasta dicho momento y el valor 1 a partir de abril de 2008. La variable $\mathrm{T}_{2}$ es una variable de conteo que toma el valor 0 con anterioridad a la apertura del procedimiento sancionador, tomando el valor 1 en abril de 2008, 2 en mayo y así sucesivamente. $\mathrm{D}_{3}$ es una variable ficticia que toma el valor 1 a partir del mes en el que la CNC adoptó la resolución, es decir, desde el mes de octubre de 2009 inclusive, y cero en otro caso. $T_{3}$ es una variable de conteo que toma el valor 1 en octubre de 2009, 2 en noviembre, y así sucesivamente. Por último, $\mathrm{D}_{4}$ se refiere a la fecha en la se dicta sentencia en el recurso presentado por CEOPAN ante la Audiencia Nacional y se estima parcialmente reduciendo la sanción en un 50 por 100 a la asociación (Noviembre de 2011), tomando el valor 1 desde noviembre inclusive y cero antes. $\mathrm{T}_{4}$ es una variable de conteo que toma el valor 1 en noviembre de 2011, 2 en diciembre de 2011, y así sucesivamente. Finalmente la variable Input se refiere al precio del trigo blando panificable, que se toma como variable de control al ser la principal referencia utilizada en el sector para la fijación del precio del pan.

La regresión se ha estimado en logaritmos y los principales resultados aparecen reflejados en el Cuadro 4. Todos los coeficientes estimados resultan significativamente diferentes de cero, excepto los correspondientes a las variables ficticias de la última fase del proceso de intervención relativa a la adopción de la resolución por parte del Consejo de la CNC y a la fecha en la que la Audiencia Nacional dictó sentencia en el recurso interpuesto por CEOPAN. 


\section{CUADRO 4}

\section{EFECTOS DE LA INTERVENCIÓN DE LAS AUTORIDADES DE LA COMPETENCIA SOBRE EL PRECIO DEL PAN}

\begin{tabular}{|l|c|c|}
\hline & Parámetro & Estadístico t \\
\hline Constante & 1,7484 & 124,83 \\
\hline$T$ & 0,0019 & 86,71 \\
\hline$D_{1}$ & 0,0064 & 3,37 \\
\hline$T_{1}$ & 0,0040 & 9,63 \\
\hline$D_{2}$ & $-0,0066$ & $-3,43$ \\
\hline$T_{2}$ & $-0,0054$ & $-9,78$ \\
\hline$D_{3}$ & $-0,0018$ & $-0,91$ \\
\hline$T_{3}$ & $-0,0006$ & $-3,05$ \\
\hline$D_{4}$ & 0,0027 & 1,42 \\
\hline$T_{4}$ & 0,0005 & 3,21 \\
\hline Input & 0,0356 & 5,50 \\
\hline$R^{2}$ & 0,99 & \\
\hline
\end{tabular}

La primera variable ficticia presenta un coeficiente estimado positivo, indicando que en la fecha en que se conoce la inspección de la $\mathrm{CNC}$, se produjo un aumento de los precios. De hecho, la subida en el precio del pan más importante tuvo lugar en los meses posteriores a esa inspección, con una variación media mensual estimada del 0,6 por 100 que, en cualquier caso, no debería ser atribuida a la misma, sino más bien a los efectos de las declaraciones y notas de prensa publicadas en los medios en aquellos meses. De hecho, este resultado puede ser interpretado de diferentes formas. En primer lugar, ya se conocían las recomendaciones de subidas de precios hechas por las asociaciones del sector en el momento de realizarse la inspección, pero estas recomendaciones colectivas aún no se habrían aplicado. En este caso estaríamos hablando de la existencia de un cierto retraso en la repercusión de esas recomendaciones en el precio final del bien. En segundo lugar, aun cuando se efectuó la inspección en la sede de CEOPAN, esta asociación, y por ende la industria, no consideró que este hecho pudiese dar lugar a la apertura de un procedimiento sancionador, y continuó su política sin alertar del peligro de una potencial intervención de la CNC en el sector, al menos inicialmente. En cualquier caso, este resultado parece indicar que la actuación por parte de las autoridades de la competencia estaba justificada a tenor del importante cambio registrado en el precio del pan. 
Por otra parte, los resultados muestran que antes de la intervención, el precio del pan venía incrementándose en torno a un 0,19 por 100 de promedio mensual ${ }^{21}$. Cabe destacar que los incrementos más significativos tenían lugar siempre en los primeros meses de cada año (véase Gráfico 3). Además, el coeficiente estimado para la variable de conteo correspondiente a la fecha a partir de la cual se conoce que ha tenido lugar la inspección, es negativa, indicando la existencia de un efecto permanente sobre la fijación del precio del pan desde ese momento. Así, el valor correspondiente a $\beta_{1}+\beta_{3}$, que refleja el efecto permanente a partir de la fase correspondiente al efecto de la inspección, es de 0,0059 o del 0,6 por 100 al mes, valor muy superior al existente con anterioridad. En consecuencia, desde la fecha en la que se inició la investigación hasta la fecha en la que se decidió incoar expediente sancionador a la mayoría de asociaciones se produjo un importante cambio de tendencia en el precio final del pan.

El efecto permanente de la apertura del procedimiento sancionador vendría dado por $\beta_{1}+\beta_{3}+\beta_{5}$, que es el principal resultado de nuestro análisis por cuanto nos va a medir los efectos permanentes de la intervención de las autoridades de la competencia sobre la fijación del precio del pan. La suma de estos coeficientes es de 0,005 , o equivalentemente, del 0,05 por 100 de incremento del precio por mes, valor muy reducido y que indica que los precios, a partir de este momento, se mantienen prácticamente constantes, produciéndose otro importante cambio de tendencia en el precio del pan, en este caso haciéndose prácticamente horizontal la tendencia del precio del pan en el tiempo.

Por lo que se refiere a la fase en la cual ya se había resuelto el expediente y había finalizado la vía administrativa, el coeficiente estimado de la variable ficticia es no significativamente diferente de cero, no existiendo ningún efecto de impacto con la resolución del expediente sancionador, mientras que la nueva tendencia, $\beta_{1}+\beta_{3}+\beta_{5}+\beta_{7}$, toma un valor de $-0,00018$, prácticamente cero, indicando que el precio del pan sigue siendo constante. Finalmente, se obtiene un resultado muy similar al anterior cuando se estudia la fecha en la que la Audiencia Nacional dictó sentencia estimando parcialmente el recurso presentado por CEOPAN. De tal manera que tampoco se observa ningún cambio de tendencia en este caso, por lo que los precios se mantienen prácticamente constantes desde el mes en el que se decidió la incoación del expediente sancionador a la mayoría de asociaciones, y CEOPAN envió la circular informativa a sus miembros, hasta la actualidad (véase Gráfico 3).

Los resultados obtenidos anteriormente plantean diversos interrogantes sobre la efectividad de la intervención de las autoridades de la competencia. En principio, resulta claro que la intervención de las autoridades puso freno al continuo aumento del precio del pan que se había producido hasta ese momento. Los resultados de la estimación evidencian el indiscutible cambio de tendencia que se produce a partir de la intervención de esas autoridades en el precio del pan, aun cuando se controla

${ }^{21}$ Dado que el modelo ha sido estimado en términos logarítmicos, el efecto del coeficiente de la variable ficticia en la variable dependiente se interpreta como el cambio porcentual en el precio. Este impacto se calcula como 100x $\left[\exp \left(\beta_{\mathrm{i}}\right)-1\right]$, donde $\beta_{\mathrm{i}}$ es el valor estimado del coeficiente de la variable ficticia. 
por el precio de la principal materia prima de referencia. Desde este punto de vista, se podría considerar que la intervención fue efectiva por cuanto disuadió y evitó comportamientos no competitivos que llevaban a incrementos continuos en el precio del pan.

Sin embargo, el principal resultado que encontramos es el cambio de comportamiento en la evolución del precio del pan que se produce a partir de un momento determinado en la intervención de la CNC: abril de 2008. En efecto, a partir de ese momento, los precios adoptan una senda temporal prácticamente constante, que se mantiene hasta el final de la muestra, es decir, más allá del momento en que la Audiencia Nacional había dictado sentencia en el recurso presentado por CEOPAN. Este resultado, cuanto menos llamativo, tiene dos posibles explicaciones derivadas de los efectos de la propia intervención de las autoridades de la competencia. La primera es que la intervención de las autoridades de la competencia rompe el mecanismo de transmisión de información que utilizaba la asociación de la industria para comunicarse con los operadores en la misma (en este sentido, resulta importante tener presente la atomización presente en esta industria), de tal forma que habría desaparecido la política de precios a nivel del sector. Ante la rotura de este mecanismo de transmisión, los precios permanecen fijos a lo largo del tiempo. En este caso, podríamos considerar que la intervención ha tenido el efecto perseguido, al romper las prácticas de fijación de precios que alteraban la competencia en el sector. Por tanto, el fenómeno de histéresis observado en los precios obedecería a la ausencia de una política coordinada de fijación de precios, tal y como había existido hasta el momento. No obstante, si bien es cierto que los precios no suben, tampoco bajan, y esto aun cuando, tras la intervención, se habrían producido fuertes fluctuaciones justamente en el precio de la materia prima cuya subida a mediados de 2007 había sido utilizada para justificar los anuncios de aumentos del precio del pan en las declaraciones y notas de prensa publicadas (véase Gráfico 4). Esto apoyaría nuestro argumento de que el mecanismo previo de coordinación en las políticas de fijación de precios había quedado roto. Nótese que en el año 2012 también se produce un nuevo repunte en el precio del trigo blando panificable, de similar cuantía al ocurrido en 2007, pero no existe ninguna reacción del sector a dicho repunte.

La segunda posible explicación es que la industria, como reacción a la intervención de las autoridades de la competencia, habría adoptado una estrategia diferente respecto a la coordinación en las políticas de precios que había llevado anteriormente. En un nuevo entorno, donde los participantes en la industria han aprendido y conocen las señales que alertan a las autoridades de la competencia sobre la posible existencia de acuerdos o recomendaciones para la fijación de precios, estos participantes podrían haber optado por coordinarse tácitamente para que el precio del pan, alcanzado después de que las recomendaciones hubiesen tenido su efecto, no sufriera variaciones significativas. Por tanto, esta posibilidad supondría que el mantenimiento del precio constante en el tiempo simplemente estaría reflejando una respuesta estratégica de la industria, dada la presencia y vigilancia de las autoridades de la competencia, compatible con un nuevo periodo de colusión tácita. 
GRÁFICO 3

SERIE TEMPORAL INTERRUMPIDA DEL PRECIO DEL PAN

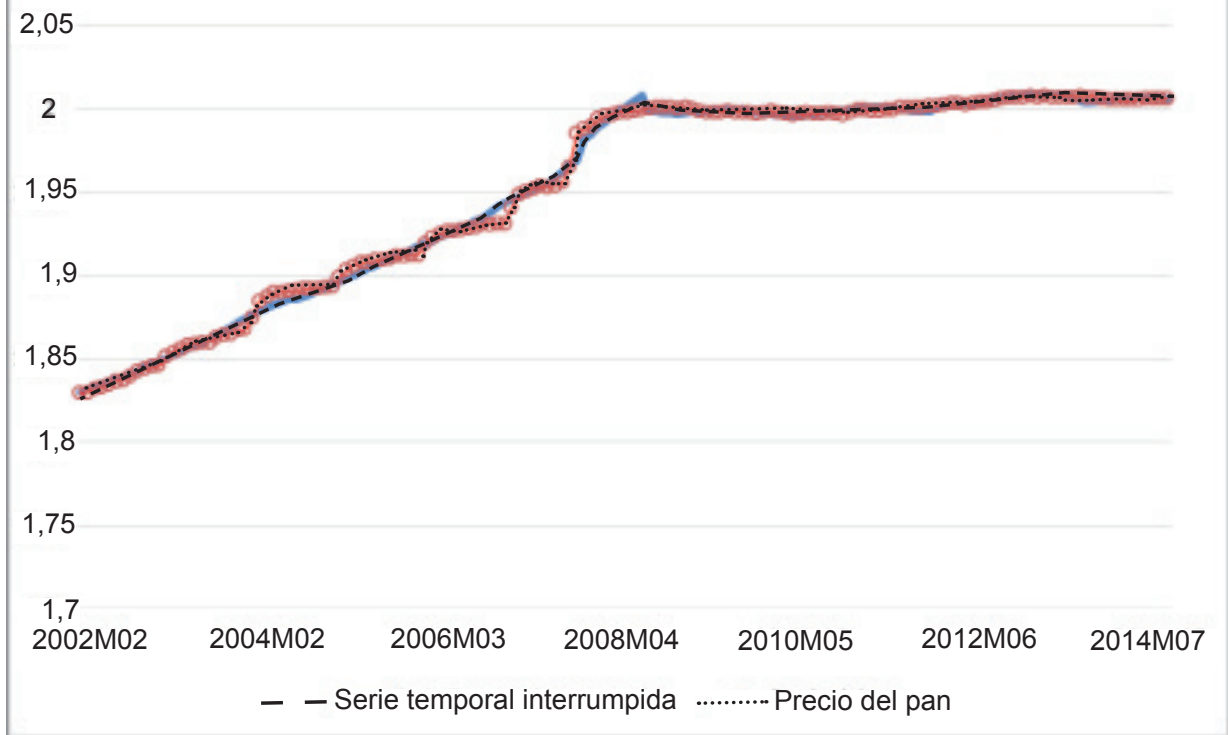

\section{GRÁFICO 4}

EVOLUCIÓN DEL PRECIO DEL TRIGO BLANCO PANIFICABLE

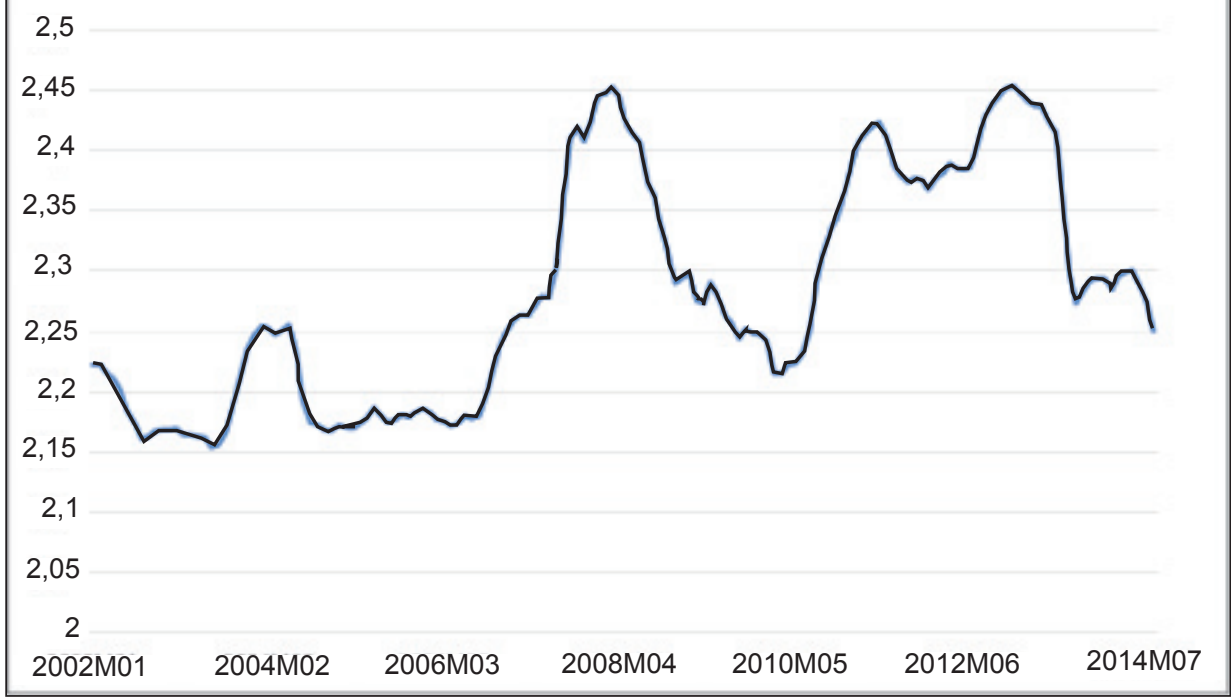




\section{Conclusiones}

La intervención de las autoridades de la competencia en una determinada industria como consecuencia de la detección de conductas o prácticas anticompetitivas, puede dar lugar a un cambio en la estrategia de coordinación entre las empresas de dicha industria. Así, es de esperar que las industrias aprendan aquellos elementos o señales que las autoridades de la competencia pueden considerar como indicios de infracciones de las normas de la competencia. Por consiguiente, si pretendemos evaluar la efectividad de una intervención es necesario identificar y cuantificar los efectos disuasorios y correctores que dicha intervención provoca a lo largo del tiempo.

En este trabajo hemos analizado el comportamiento del precio del pan como respuesta a las decisiones adoptadas, desde finales del año 2007, por las autoridades de la competencia españolas y que afectaron a asociaciones pertenecientes a esta industria. En particular, a raíz de la intervención de la CNC se observan importantes cambios en la evolución del precio del pan a lo largo del tiempo. El modelo estimado muestra que, a partir de la fecha en la que se tiene conocimiento de una inspección en la sede de la asociación que agrupa a la mayoría de asociaciones de fabricantes y expendedores de pan, se produce efectivamente un cambio de tendencia al alza en el precio del pan, confirmando la existencia de efectos causados por los comportamientos anticompetitivos que dieron lugar al inicio de la investigación por parte de las autoridades de la competencia. Dicho comportamiento desapareció una vez que se decidió la incoación de expediente sancionador a la mayoría de asociaciones en el sector de la alimentación y la asociación nacional de fabricantes y expendedores de pan remitió una circular alertando de los peligros de continuar realizando declaraciones sobre subidas de precios del pan. En ese momento tuvo lugar un nuevo cambio de tendencia en la evolución del precio del pan en el tiempo, a partir de entonces el precio se ha mantenido prácticamente constante hasta la actualidad. Este último resultado parece indicar la ruptura del mecanismo de transmisión de información entre la asociación y las empresas respecto a la política de fijación de precios a llevar a cabo en el mercado, tal y como se había mantenido hasta ese momento.

Sin embargo, la importante histéresis observada en la evolución del precio a partir de la fecha de la incoación del mencionado expediente sancionador y el posterior envío de la nota informativa por parte de la asociación nacional, que refleja una total insensibilidad a las variaciones en el precio de la materia prima utilizada anteriormente como principal referencia, podría indicar que sigue existiendo algún tipo de coordinación en la industria, por la que se podría haber adoptado una estrategia consistente en mantener el precio del pan en torno a los niveles alcanzados en las fechas previas a la incoación del expediente sancionador, al ser suficientemente elevados, y minimizar las fluctuaciones del mismo. 


\section{Referencias bibliográficas}

[1] BLOCK, M. K., F. C. NOLD y J. G. SIDAK (1981): «The Deterrent Effect of Antitrust Enforcement», Journal of Political Economy, 89, pp. 429-445.

[2] CAMPBELL, D.T. (1969): «Reforms as experiments», American Psychologist, 24, pp. 409-429.

[3] CAMPBELL, D.T. y J.C. STANLEY (1963): «Experimental and quasi-experimental designs for research». Chapter 5 en Handbook of Research on Teaching, N.L. GAGE (Ed.), Chicago: Rand McNally.

[4] FROEB, L. M., R. A. KOYAK y G. J. WERDEN (1993): «What is the effect of bidrigging on prices?», Economic Letters, 42, pp. 419-423.

[5] HARRINGTON, J. E. (2004): «Post-Cartel Pricing during Litigation», Journal of Industrial Economics, 52, pp. 517-533.

[6] LEWIS-BECK, M. S. (1979): «Some economic effects of revolution: Models, measurement, and the Cuban evidence», American Journal of Sociology, 84(5), pp. 1127-1149.

[7] LEWIS-BECK, M. S. y J. R. ALFORD (1980): «Can government regulate safety? The coal mine example», American Political Science Review, 74(3), pp. 745-756.

[8] LEWIS-BECK, M.S. (1986): «Interrupted Time Series», Chapter 9 en W.D. BERRY y M. S. LEWIS-BECK (eds.), New Tools for Social Scientists: Advances and Applications in Research Methods, Beverly Hills: Sage Publications.

[9] MAPA (2003): «Diagnóstico y Análisis Estratégico del Sector Agroalimentario Español. Análisis de la cadena de producción y distribución del sector de molinería y sus transformados», http://www.magrama.gob.es/es/alimentacion/temas/consumo-ycomercializacion-y-distribucion-alimentaria/informe_molineria_tcm7-7946.pdf

[10] MARM (2009): «Estudio de la cadena de valor y formación de precios del sector del pan», http://www.magrama.gob.es/es/alimentacion/servicios/observatorio-de-preciosde-los-alimentos/estudio_pan_tcm7-14630.pdf

[11] McDOWALL, D., R. McClEARY, E.E. MEIDINGER, y R. A. HAY, Jr. (1980): «Interrupted Time Series Analysis», Sage University Paper Series: Quantitative Applications in the Social Sciences, J. L. SULLIVAN (ed.), Beverly Hills: Sage Publications.

[12] MNCUBE, L. (2013): «The South African Wheat Flour Cartel: Overcharges at the Mill», Journal of Industry, Competition and Trade, disponible online, próxima publicación.

[13] MUELLER, W. F. y R. C. PARKER (1992): «The Bakers of Washington Cartel: TwentyFive Years Later», Review of Industrial Organization, 7, pp. 75-82.

[14] NEWMARK, C. M. (1988a): «Does Horizontal Price Fixing Raise Price? A Look at The Bakers of Washington Case», Journal of Law and Economics, 31, pp. 469-484.

[15] NEWMARK, C. M. (1988b): «Is Antitrust Enforcement Effective?», Journal of Political Economy, 96, pp. 1315-1328.

[16] ORDÓÑEZ DE HARO, J. M. y J. L. TORRES (2014): «Price Hysteresis after Antitrust Enforcement: Evidence from Spanish Food Markets», Journal of Competition Law and Economics, 10, pp. 217-256.

[17] PARKER, R. C. (1969): «The Baking Industry», Antitrust Law and Economics Review, 4, pp. 111-122. 
[18] STANO, M. y H. HOTELLING (1991): «Regression Analysis in Litigation: Some Overlooked Considerations», Journal of Legal Economics, 1, pp. 68-76.

[19] STIEGERT, K. W. (2002): «The producer, the baker, and a test of the mill price-taker», Applied Economic Letters, 9, pp. 365-368. 


\section{SUSCRIPCIÓN ANUAL}

\begin{tabular}{|c|c|c|c|}
\hline & $\begin{array}{l}\text { ESPAÑA } \\
1 \text { año }\end{array}$ & $\begin{array}{c}\text { UNIÓN EUROPEA } \\
1 \text { año }\end{array}$ & $\begin{array}{l}\text { RESTO DEL } \\
\text { MUNDO } \\
1 \text { año }\end{array}$ \\
\hline SUSCRIPCIÓN & $30,00 €$ & $40,00 €$ & $40,00 €$ \\
\hline $\begin{array}{l}\text { Gastos de envío } \\
\text { España }\end{array}$ & $2,36 €$ & $10,04 €$ & $16,10 €$ \\
\hline $\begin{array}{c}\text { Más 4\% de IVA. } \\
\text { Excepto Canarias, Ceuta y Melilla }\end{array}$ & $1,29 €$ & & \\
\hline TOTAL & $33,65 €$ & $50,04 €$ & $56,10 €$ \\
\hline
\end{tabular}

\section{EJEMPLARES SUELTOS}

\begin{tabular}{|c|c|c|c|}
\hline \multicolumn{4}{|c|}{ CUADERNOS ECONÓMICOS DE INFORMACIÓN COMERCIAL } \\
\hline & $\begin{array}{c}\text { ESPAÑA } \\
1 \text { ejemplar }\end{array}$ & $\begin{array}{c}\text { UNIÓN EUROPEA } \\
1 \text { ejemplar }\end{array}$ & $\begin{array}{c}\text { RESTO DEL } \\
\text { MUNDO } \\
1 \text { ejemplar }\end{array}$ \\
\hline NÚMERO SUELTO & $18,00 €$ & $23,00 €$ & $23,00 €$ \\
\hline $\begin{array}{c}\text { Gastos de envío } \\
\text { España }\end{array}$ & $1,18 €$ & $5,02 €$ & $8,05 €$ \\
\hline $\begin{array}{c}\text { Más 4\% de IVA. } \\
\text { Excepto Canarias, Ceuta y Melilla }\end{array}$ & $0,77 €$ & $\mathbf{2 8 , 0 2} €$ & $31,05 €$ \\
\hline TOTAL & $\mathbf{1 9 , 9 5 €}$ & & \\
\hline
\end{tabular}

\section{DATOS}

Nombre y apellidos

Empresa

Domicilio

D.P.

N.I.F

Teléf.

Email
Transferencia a la cuenta de ingresos por venta de publicaciones del Ministerio de Economía y Competitividad.

IBERCAJA. Calle Alcalá 29. 28014 MADRID (ESPAÑA) CÓDIGO CUENTA CLIENTE: 2085-9252-07-0330598330 CÓDIGO BIC DE IBERCAJA: CAZRES2Z

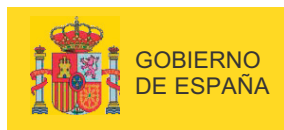

\section{MINISTERIO}

DE ECONOMIA Y

COMPETITIVIDAD
SUBSECRETARIA

SECRETARIAA GENERAL TÉCNICA

SUBDIRECCIÓN GENERAL

DE ESTUDIOS, INFORMACIONY

PUBLICACIONES

Suscripciones y ventas por correspondencia:

Paseo de la Castellana, 162, 8 a Planta 28046 Madrid. Teléfono 91583.55.07/06

Suscripciones a través de la página web del Ministerio de Economía y Competitividad

distribucionpublicaciones@mineco.es 


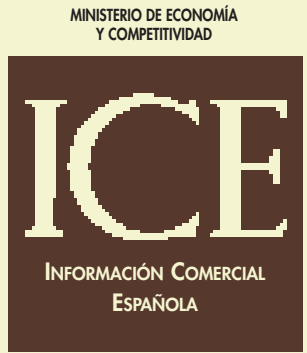

\section{CUADERNOS \\ ECONÓMICOS}

\section{ÚLTIMOS NÚMEROS PUBLICADOS}

54. Economía experimental

55. Especificación y evaluación de modelos econométricos (I)

56. Especificación y evaluación de modelos econométricos (II)

57. Política de defensa de la competencia

58. Las fuentes de crecimiento

59. Integración económica

60. Juegos dinámicos

61. Distribución de la renta y crecimieto económicos

62. La Nueva Economía Política

63. Aspectos del mercado de trabajo español

64. Crisis y reformas de los sistemas de Seguridad Social: Temas a debate (I)

65. Crisis y reformas de los sistemas de Seguridad Social: Temas a debate (II)

66. Microeconometría y conducta: Aplicaciones para el caso español

67. La economía de la salud

68. Modelos de microsimulación

69. Instrumentos derivados

70. Nuevas tendencias en Historia Económica

71. Diseño y evaluación de políticas de protección ambiental

72. Decisiones de inversión y adopción de nuevas tecnologías

73. La gestión de la actividad innovadora en las empresas

74. Capital humano y empleo

75. Desigualdad, equidad y eficiencia en salud y servicios sanitarios

76. Contribuciones recientes a la Economía Industrial

77. Contribuciones a la Economía Experimental

78. Aportaciones recientes a la Economía Industrial

79. Contribuciones a la economía de la energía

80. Evaluación económica de infraestructuras de transporte

81. Análisis económico de las telecomunicaciones en España

82. Comercio internacional, empresas y competitividad

83. Economía de las energías renovables

84. Mejorar la productividad: un reto pendiente en la economía española

85. Temas actuales de Economía Política

86. Gestión ambiental de las organizaciones

87. Inmigración y crisis económica en España

88. Defensa de la Competencia en España: un análisis sectorial

\section{NÚMEROS EN PREPARACIÓN}

89. Contribuciones a la Economía de la Innovación: análisis de la I+D+i empresarial 

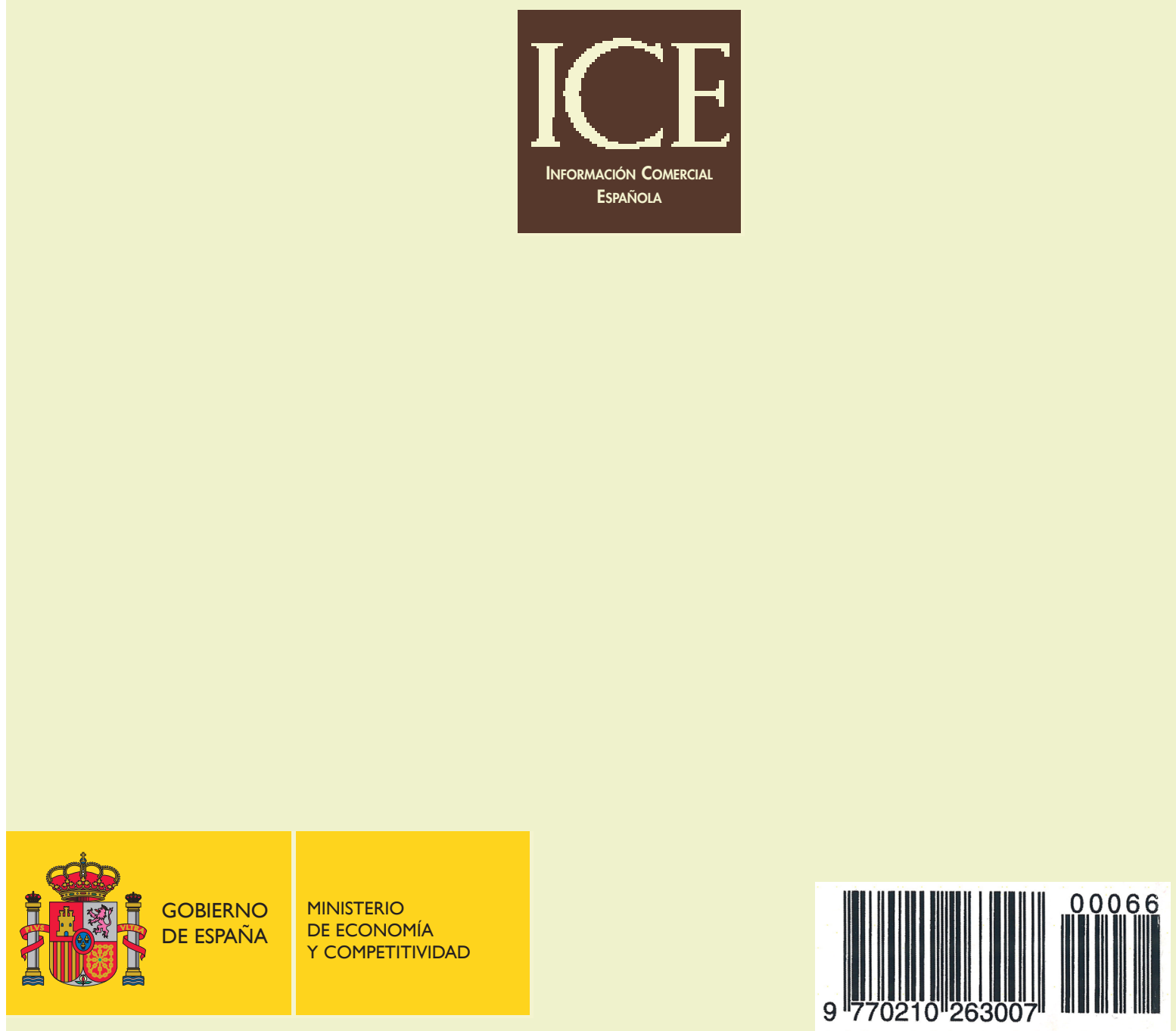

P.V.P.: 19,95 euros (I.V.A. incluido) 